\title{
Avaliando o Efeito Contágio entre Economias durante Crises Financeiras
}

\author{
Fernanda Finotti Cordeiro Perobelli \\ Professora - Universidade Federal de Juiz de Fora (UFJF) \\ Endereço para contato: Campus Universitário - Faculdade de Economia - Bairro Martelos \\ Juiz de Fora - MG - CEP: 36900-330 - E-mail: fernandafinotti.perobelli@ufff.edu.br
}

\section{Tatiana Ladeira Vidal}

Pesquisadora - Faculdade de Economia, Administração e Contabilidade (FEAVUSP)

Endereço para contato: Av. Prof. Luciano Gualberto, 908 - São Paulo - SP - CEP: 05508-010

E-mail: tl.vidal@yahoo.com.br

\section{José Roberto Securato}

Professor - Faculdade de Economia, Administração e Contabilidade (FEA/USP)

Endereço para contato: Av. Prof. Luciano Gualberto, 908 - sala G 168 - FEAVUSP - São Paulo - SP

CEP: 05508-010 - E-mail: securato@usp.br

Recebido em 15 de agosto de 2012. Aceito em 29 de maio de 2013.

\section{Resumo}

O objetivo deste trabalho, a partir das metodologias sugeridas por Forbes e Rigobon (2002) e Corsetti, Pericoli e Sbracia (2005), é verificar indícios de efeito contágio entre quinze economias em oito episódios de crises financeiras. Conclui-se que o modelo de Corsetti, Pericoli e Sbracia (2005), como esperado, apresentou-se mais eficiente em encontrar indícios de efeito contágio, uma vez que abrange variações nas componentes dos retornos não consideradas pelo modelo de Forbes e Rigobon (2002). Os resultados, corroborados por testes de robustez, indicam a crise asiática de 1997 como a mais contagiosa, seguida pelo ataque terrorista de 11 de setembro de 2001, crise brasileira de 1999, bolha da internet de 2000 e crise do Subprime. Os outros episódios não apresentaram indícios de contágio, o que indica choques restritos ao país de origem da crise.

\section{Palavras-Chave}

crises financeiras, contágio, interdependência, análise fatorial

\begin{abstract}
This study aims, using the Forbes and Rigobon (2002) and Corsetti, Pericoli and Sbracia (2005) suggested methodologies, to verify the contagion effect among fifteen economies during eight financial crisis. The study conclusion is that the Corsetti, Pericoli and Sbracia (2005) model is more efficient to detect contagion, once it considers the variance of the returns components that are not considered at Forbes and Rigobon (2002) approach. The results are corroborated by robustness tests. The most contagion episode is the 1997 Asian crisis, followed by the terrorist attack of 2001 September $11^{\text {th }}, 1999$ Brazilian crisis, 2000 Internet bubble and the Subprime crisis. The others episodes do
\end{abstract}


not present any evidence of contagion effect. This fact indicates that the shocks were restricted to the crisis origin country.

\section{Keywords}

financial crisis, contagion effect, interdependence, factor analysis

\section{JEL Classification}

G01

\section{Introdução}

Com a intensificação das relações entre os países, desequilíbrios iniciados em um país são rapidamente transmitidos para a economia de outros, muitas vezes de forma intensa e imprevisível. Essa situação pode ser caracterizada como crise financeira. É vasta a literatura sobre as causas e consequências desses desequilíbrios, assim como estudos que propõem formas de prevê-los. Reinhart e Rogoff (2010) apresentam uma compilação robusta de informações sobre crises financeiras desde 1300 até a crise norte- americana de 2008. De acordo com esses autores, apesar de acontecerem em épocas diferentes e sobre ativos diferentes, os fundamentos das crises financeiras se repetem. Por exemplo, crises geralmente acontecem após períodos de amplo desenvolvimento econômico, abundância de crédito e expectativas de retornos anormais infinitos.

O trabalho de Reinhart e Rogoff (2010) defende a ideia de que as economias apresentam uma síndrome que faz com que o ciclo de crises financeiras nunca tenha um fim. Trata-se da síndrome do desta vez é diferente. De acordo com os autores, "[...] ela se esteia na crença convicta de que as crises financeiras são coisas que acontecem com outras pessoas, em outros países e em outras épocas" (Reinhart, Rogoff, 2010, p.14), que as lições foram aprendidas com as crises passadas, que os novos métodos de avaliação de ativos são mais robustos e não apresentam os problemas dos antigos, que as inovações tecnológicas e as políticas públicas são infalíveis. Entretanto, historicamente, verifica-se que os momentos que antecedem crises financeiras são, de alguma forma, semelhantes. 
Ao longo da década de 1990, graves crises assolaram diversos países com características econômicas e culturais diferentes. Essas turbulências recentes nas finanças internacionais suscitaram uma série de discussões e motivaram a geração de novas linhas de pesquisas sobre o assunto. Nas pesquisas teóricas, o objetivo central tem sido o de refinar o entendimento acerca das possíveis causas das crises recentes, bem como o seu timing e formas de propagação. Já em relação às pesquisas empíricas, o objetivo tem sido o levantamento de indicadores que possam evidenciar a iminência de uma crise, para, com isso, buscar maneiras de prevenir ou responder eficientemente a futuras crises (Murta, Brasil, Samohyl, 2003).

Embora os estudos das diversas crises financeiras que assolaram os mercados internacionais possam ser analisados a partir de diferentes visões, os autores concordam que a integração dos mercados fez com que os choques se propagassem mais rapidamente pelos canais de transmissão. De acordo com Pericoli e Sbracia (2003), nos últimos anos, tem-se presenciado a propagação de turbulências financeiras entre países geograficamente distantes, com diferentes estruturas financeiras e sem ligações econômicas significantes. Assim, questões como "quais são os canais de transmissão de crises financeiras ? Devem os investidores e gestores de políticas econômicas preocuparem-se com o aumento dos comovimentos de preços entre os países?" têm levado os estudiosos a refletir sobre as diversas vertentes de causas, previsões e transmissão dos diversos tipos de crises financeiras.

De acordo com Dornbusch, Park e Claessens (2000), o advento de uma crise em determinado país pode levar os investidores a reestruturarem seus portfólios, reconsiderando seus investimentos em diversos mercados, sem levar em conta nem mesmo as diferenças existentes entre os fundamentos macroeconômicos desses mercados. Esse tipo de transmissão de choques pode dar origem ao efeito contágio, causado por fenômenos irracionais, como pânicos financeiros, comportamentos de efeito manada, perda de confiança, aumento da aversão ao risco, entre outros. De acordo com Bergmann et al. (2010), o termo contágio tornou-se conhecido a partir da análise das crises da década de 1990, quando choques originados em determinado mercado estenderam-se a vários mercados de outros países e dificilmente conseguiam ser explicados por mudanças nos fundamentos macroeconômicos. 
Segundo Forbes e Rigobon (2002), existe certa integração pré-existente entre as economias dos países. Durante o período de turbulência financeira, essa relação apresenta uma tendência a se mostrar mais intensa. Essa intensidade pode ser suficiente para promover quebras na estrutura previamente existente de transmissão de choques entre dois países. Quando isso acontece, os autores caracterizam o episódio como efeito contágio, ou seja, choques ocorridos em determinada economia contagiaram a economia de outro país, independentemente da situação dos fundamentos macroeconômicos dos dois países em questão. Por outro lado, quando há um aumento normal na intensidade das relações, este pode ser classificado como interdependência, oriunda das relações econômicas preexistentes entre os países.

Com o aumento da integração entre as economias, espera-se que, para constituir contágio, sejam necessárias turbulências cada vez mais severas, capazes de ocasionar quebras estruturais. Uma das principais relevâncias dos testes de efeito contágio é, a partir do entendimento de tal fenômeno, antever impactos de turbulências ocorridas entre economias diversas no intuito de, através de modelos robustos, antecipar intervenções político-econômicas e tornar os impactos de choques internacionais os mínimos possíveis.

Outra questão importante dessa antecipação é a avaliação de seu impacto nas decisões de investimento em carteiras diversificadas. De acordo com a teoria de carteiras de Markowitz (1952), a formação de carteiras com ativos não positiva e perfeitamente correlacionados permite um benefício ao minimizar o risco próprio dos ativos que compõem a carteira (advindo das decisões tomadas no âmbito corporativo). O único componente de risco a que o investidor deveria se submeter, dependendo do seu comportamento frente ao risco, seria o risco sistêmico, ou seja, o risco advindo do sistema econômico a que os ativos estão submetidos, capaz de causar uma resposta comum nos retornos dos ativos. ${ }^{1}$ Assim, considerando a possibilidade de investimento entre países, montar uma carteira com ativos de países diferentes seria beneficiar-se da redução do risco próprio também

\footnotetext{
1 Sharpe (1964) definiu formalmente o risco sistêmico (mensurado pelo beta de um ativo $i$, definido como a covariância do retorno do ativo $i$ com o retorno do mercado $g$ por unidade de variância de $g$ ) como a variação do retorno de um ativo (Ri) decorrente de variações no retorno de $\mathrm{g}(\mathrm{Rg})$, sendo g o conjunto eficiente de ativos de risco no ponto de tangência da Reta do Mercado de Capitais (CML), cujo intercepto é dado pela Taxa Livre de Risco (rf), à Fronteira Eficiente de Markowitz (1952). Já o risco próprio seria definido, ex post, como o erro-padrão $(e)$ da Reta do Mercado de Títulos $\left(\mathrm{Ri}=\mathrm{rf}+\operatorname{beta}^{*}(\mathrm{Rg}-\mathrm{rf})+\mathrm{e}\right)$.
} 
das economias às quais os ativos pertençam, restando apenas o risco sistêmico (respostas de cada país a movimentos globais). Porém, caso haja espraiamento da crise, espera-se uma redução na razão entre risco próprio de países que estejam enfrentando crises e risco sistêmico. Caso esta situação ocorra, a mitigação do risco próprio da carteira através de sua composição com ativos de diferentes países não seria mais tão significante justamente quando suas propriedades são mais necessárias: em momentos de crises financeiras (Billio e Caporin, 2010; Pericoli e Sbracia, 2003).

O principal objetivo do presente trabalho é identificar indícios do efeito contágio nos mercados de capitais mais representativos do mundo, utilizando a metodologia sugerida por Corsetti, Pericoli e Sbracia (2005). A partir de críticas ao trabalho de Forbes e Rigobon (2002), os autores propõem uma metodologia alternativa, que afirmam não ser enviesada por considerar a variância dos retornos oriunda dos fatores específicos do país de origem da crise, quando comparada à variância oriunda do fator sistêmico.

O efeito contágio será testado empiricamente, considerando os principais momentos de turbulências internacionais ocorridos desde a década de 1990 até a primeira década do século XXI. Assim, ampliou-se a amostra em relação ao teste empírico de Corsetti, Pericoli e Sbracia (2005), que se limitou à crise Asiática. Essa ampliação é uma contribuição relevante devido às particularidades de cada crise financeira, como a situação dos fundamentos macroeconômicos, intensidade, rapidez e canais de transmissão dos choques do país de origem das crises em relação ao resto do mundo.

Como objetivo secundário, o estudo irá comparar os resultados obtidos a partir do emprego do teste empírico de Corsetti, Pericoli e Sbracia (2005) com os resultados dito enviesados por esses autores que seriam obtidos no teste de Forbes e Rigobon (2002), no intuito de evidenciar a importância do comportamento heterocedástico das variâncias dos riscos próprios e sistêmico nos testes empregados. 


\section{Referencial Teórico}

Vários trabalhos utilizaram alterações nos coeficientes de correlação entre retornos financeiros de duas economias como indicativo do efeito contágio, além de testarem alterações nos parâmetros do processo gerador dos retornos no intuito de verificar quebras estruturais em momentos de crises. A lógica desses testes está sumarizada abaixo. Suponha que o retorno de um país i siga a relação linear apresentada pela Equação 1:

$$
r_{i}=\beta_{0}+\beta_{1} r_{j}+\varepsilon_{i}
$$

onde $\beta_{0}$ é um valor constante, $r_{j}$ o retorno de um segundo país e $\beta_{1}$ a sensibilidade do país $\mathbf{i}$ a variações no retorno do país $\mathbf{j}$, ou seja, a força de inter-relação entre esses dois mercados. Além desses termos, há um fator aleatório $\varepsilon_{i}$ que representa a componente de retorno do país i condicionada a variações em sua própria economia, independente de $r_{j}$. Esta equação representa a estrutura de inter-relação entre $\mathbf{i}$ e $\mathbf{j}$, ou seja, nela estão considerados todos os mecanismos de transmissão de choques existentes entre os dois países.

De maneira bastante interessante, Corsetti, Pericoli e Sbracia (2005) defendem a ideia de que a composição do retorno de cada país seja escrita de maneira similar ao exposto nos modelos de um fator (classificação em que se enquadra o Capital Asset Pricing Model, ou CAPM, defendido por Sharpe em 1964 e amplamente utilizado como modelo gerador de retornos justos nos mercados financeiros), onde o retorno de um ativo é função de um valor autônomo ou livre de risco (preço do tempo), de um prêmio pelo risco sistêmico ajustado pela sensibilidade do ativo a esse sistema (beta) e do risco próprio (diversificável) do ativo (Sharpe, 1964). Assim, os retornos dos países i e j podem ser escritos conforme as Equações 2 e 3, respectivamente:

$$
\begin{aligned}
& r_{i}=\alpha_{i}+\gamma_{i} f+\varepsilon_{i} \\
& r_{j}=\alpha_{j}+\gamma_{j} f+\varepsilon_{j}
\end{aligned}
$$

onde $\alpha_{i}$ e $\alpha_{j}$ são constantes e representam o retorno autônomo (livre de risco); $\gamma_{i}$ e $\gamma_{j}$ são as cargas fatoriais (sensibilidades) dos 
países a um fator de risco comum/sistêmico (mesmo papel desempenhado pelo beta no CAPM); $f$ é o fator de risco comum/sistêmico entre todos os países da economia global ${ }^{2}$ e $\varepsilon_{i}$ e $\varepsilon_{j}$ são termos aleatórios ou componentes idiossincráticos dos retornos (riscos próprios de cada país).

Suponha agora que o país j seja acometido por um choque financeiro. Surgem então dois regimes diferentes: o período de tranquilidade (T) e o período de crise (C). Conforme visto na Equação 1, existe uma estrutura de relações entre os países preexistente no regime de tranquilidade (T), sumarizada pelo coeficiente $\beta_{1}$. Então, após um choque financeiro em $\mathbf{j}$, dada a inter-relação entre as economias, espera-se que esta turbulência seja sentida em i. Se esta crise alterar a estrutura de transmissão de choques existente no período $\mathbf{T}$, há indícios de efeito contágio. Caso a estrutura de transmissão de choques permaneça a mesma, é considerado que os efeitos da crise iniciada em $\mathbf{j}$ sobre o país $\mathbf{i}$ são devidos apenas à interdependência existente entre os países.

Segundo Corsetti, Pericoli e Sbracia (2010), dada uma crise financeira, espera-se verificar fatos estilizados no comportamento dos ativos, entre eles queda nos retornos, aumento de volatilidade e aumento das covariâncias e correlações. Dessa forma, entre os regimes $\mathbf{T}$ e $\mathbf{C}$, é esperado um aumento da variância nos retornos do país de origem da crise, comportamento este descrito pela Equação 4, condizente com os fatos estilizados:

$$
\operatorname{Var}\left(r_{j} \mid C\right)=(1+\delta) \operatorname{Var}\left(r_{j} \mid T\right) \Rightarrow \delta>0
$$

A variância do retorno do país j originador da crise no período de turbulência $\left(\operatorname{Var}\left(r_{j} \mid C\right)\right)$ é maior que a variância no período de tranquilidade $\left(\operatorname{Var}\left(r_{j} \mid T\right)\right)$. Este aumento da variância em $\mathbf{C}$, quando comparada à variância em $\mathbf{T}$, é representado pelo componente $(1+\delta)$, conforme Equação 5:

$$
\delta \equiv \frac{\operatorname{Var}\left(r_{j} \mid C\right)}{\operatorname{Var}\left(r_{j} \mid T\right)}-1
$$

2 Mais adiante será mostrado que esse fator de risco sistêmico, ou comum entre todos os países da amostra, bem como as cargas fatoriais (sensibilidades) de cada país da amostra a ele, serão obtidos por meio do emprego da técnica de Análise Fatorial às series de retornos dos países da amostra. 
Ao substituir a Equação 4, que representa a variância do país $\mathbf{j}$ durante o período de crise, na equação que representa a correlação entre os retornos dos países j e i, é encontrada a Equação 6 que representa a correlação entre os retornos dos países $\mathbf{i}$ e $\mathbf{j}$ durante o regime $\mathbf{C}$, ou seja, durante a crise financeira:

$$
\operatorname{Corr}\left(r_{i}, r_{j} \mid C\right)=\left[1+\frac{\operatorname{Var}\left(\varepsilon_{i}\right)}{\beta_{1}^{2}(1+\delta) \operatorname{Var}\left(r_{j} \mid T\right)}\right]^{-1 / 2}>\operatorname{Corr}\left(r_{i}, r_{j} \mid T\right)
$$

Pode-se fazer a seguinte interpretação a partir da Equação 6: de acordo com a Equação 5, é esperado que a correlação entre os países i e $\mathbf{j}$, durante o regime $\mathbf{C}$, seja maior que a correlação entre esses países no regime $\mathbf{T}$, mesmo que a inter-relação entre eles $\left(\beta_{1}\right)$ não se altere. Ou seja, mesmo que não haja contágio, i sentirá os efeitos da crise em $\mathbf{j}$ dada a interdependência existente entre eles. Até este ponto, as abordagens de Forbes e Rigobon (2002) e de Corsetti, Pericoli e Sbracia (2005) coincidem.

Assim, Forbes e Rigobon (2002) afirmam que utilizar simplesmente o aumento da correlação entre os países como variável indicativa do contágio pode levar a conclusões errôneas, sendo importante considerar que existe uma influência esperada do aumento da variância do retorno do país de origem da crise na correlação deste com outros países (aumentando-a). Forbes e Rigobon (2002), entretanto, consideram que a variância que pode influenciar a correlação entre os retornos dos países é a advinda do fator sistêmico, ou comum, uma vez que os autores assumem como premissa que a variância advinda dos fatores idiossincráticos (próprios dos países) é homocedástica ou constante, conforme conjunto de Equações 7:

$$
\begin{aligned}
& E\left(\varepsilon_{t}\right)=0 \\
& E\left(\varepsilon_{t}^{2}\right)=c<\infty
\end{aligned}
$$

Para eliminar então o viés de heterocedasticidade da variância dos retornos advinda do fator comum e ajustar o coeficiente de correlação à variância dos retornos do país de origem da crise, Forbes e 
Rigobon (2002), considerando a inexistência de endogeneidade e variáveis omissas, sugerem o cálculo de um coeficiente de correlação dito condicional, que leva em consideração o aumento da variância dos retornos do país de origem da crise, durante o período de turbulência, conforme Equação 8. Este coeficiente é ajustado ao aumento da variância dos retornos do país de origem da crise representado por $\delta$.

$$
\rho_{a j}=\frac{\rho^{*}}{\sqrt{1+\delta\left[1-\left(\rho^{*}\right)^{2}\right]}}
$$

onde $\rho^{*}$ é o coeficiente de correlação não condicional ao aumento de variância dos retornos de $\mathbf{j}$ dada uma crise, ou seja, a correlação observada, e $\delta$ é o aumento relativo da variância dos retornos do país de origem da crise, considerando os períodos T e C. Forbes e Rigobon (2002) afirmam que, devido à presença de $\delta$ (aumento da variância dos retornos do país de origem da crise) na Equação 8 , o coeficiente de correlação condicional (ajustado) será sempre maior que o coeficiente de correlação não condicional (observado) em períodos de turbulência, o que pode levar a indícios errôneos de contágio. Então, os autores propõem que o coeficiente de correlação não condicional (observado) seja ajustado a imperfeições de heterocedasticidade dos retornos. Feito o ajuste, apenas o aumento do coeficiente de correlação ajustado do período de crise, relativamente ao coeficiente de correlação ajustado de todo o período, ambos calculados pela Equação 8, constituiria contágio.

O teste de hipótese a ser realizado é representado pela Equação 9. Se o coeficiente de correlação ajustado abrangendo todo o período $\left(\rho_{a j}\right)$ for maior que o coeficiente de correlação ajustado para o período de crise $\left(\rho_{a j}^{C}\right)$, entende-se que não houve efeito contágio, mas sim interdependência entre os países. Caso o coeficiente de correlação ajustado para todo o período $\left(\rho_{a j}\right)$ seja menor ou igual ao coeficiente de correlação ajustado do período de crise $\left(\rho_{a j}^{C}\right)$, há indícios de efeito contágio.

$$
\begin{aligned}
& H_{0}: \rho_{a j}>\rho_{a j}^{C} \\
& H_{1}: \rho_{a j} \leq \rho_{a j}^{C}
\end{aligned}
$$


Já Corsetti, Pericoli e Sbracia (2005), reescrevendo a Equação 6 em função das variâncias do país de origem da crise (j) e do país afetado (i), afirmam que as correlações entre os países $\mathbf{i}$ e $\mathbf{j}$, dados os regimes $\mathbf{T}$ ou $\mathbf{C}$, podem ser representadas pelas Equações 10 e 11, respectivamente:

$$
\begin{aligned}
& \operatorname{Corr}\left(r_{i}, r_{j} \mid T\right)=\frac{1}{\left[1+\frac{\operatorname{Var}\left(\varepsilon_{i}\right)}{\gamma_{i}^{2} \operatorname{Var}(f \mid T)}\right]^{1 / 2}\left[1+\frac{\operatorname{Var}\left(\varepsilon_{j} \mid T\right)}{\gamma_{j}^{2} \operatorname{Var}(f \mid T)}\right]^{1 / 2}} \\
& \operatorname{Corr}\left(r_{i}, r_{j} \mid C\right)=\frac{1}{\left[1+\frac{\operatorname{Var}\left(\varepsilon_{i}\right)}{\gamma_{i}^{2} \operatorname{Var}(f \mid C)}\right]^{1 / 2}\left[1+\frac{\operatorname{Var}\left(\varepsilon_{j} \mid C\right)}{\gamma_{j}^{2} \operatorname{Var}(f \mid C)}\right]^{1 / 2}}
\end{aligned}
$$

Considerando a Equação 4 e as Equações 10 e 11, Corsetti, Pericoli e Sbracia (2005) reconhecem a contribuição do trabalho de Forbes e Rigobon (2002), ao considerar o viés trazido pela heterocedasticidade dos retornos, que favorece a aceitação do efeito contágio, e a tentativa de ajuste do coeficiente de correlação. Entretanto, Corsetti, Pericoli e Sbracia (2005) trazem à tona uma discussão relevante a respeito da composição da variância dos retornos. De acordo com a Equação 4, o aumento da variância dos retornos do país de origem da crise, país $\mathbf{j}$, pode advir do aumento da variância do fator comum, do aumento da variância dos fatores próprios do país j, ou dos dois (Equação 12).

$$
\begin{aligned}
& \operatorname{Var}(f \mid C)=\left(1+\delta_{1}\right) \operatorname{Var}(f \mid T) \\
& \operatorname{Var}\left(\varepsilon_{j} \mid C\right)=\left(1+\delta_{2}\right) \operatorname{Var}\left(\varepsilon_{j} \mid T\right)
\end{aligned}
$$

Dessa forma, Corsetti, Pericoli e Sbracia (2005) afirmam que considerar a componente de variância própria do retorno do país $\mathbf{j}$ como homocedástica ou constante pode ser tendencial em aceitar a hipótese de interdependência em detrimento da hipótese de contágio, 
situação que os autores afirmam acontecer com o coeficiente ajustado sugerido por Forbes e Rigobon (2002). É possível notar pelas Equações 10 e 11 que, no modelo de Corsetti, Pericoli e Sbracia (2005), o coeficiente de correlação, em ambos os regimes T e C, é influenciado de forma diretamente proporcional pela variância do fator comum, e, de forma indiretamente proporcional, pela variância dos fatores idiossincráticos dos países. Corsetti, Pericoli e Sbracia (2005) assumem algumas premissas nessa relação (Equação 13). Os autores consideram que a variância do componente próprio do país i, influenciado pela crise, deve ser constante entre os regimes, uma vez que os choques internacionais são transmitidos sistemicamente. Além disso, os componentes de riscos próprios dos países devem ser independentes entre si:

$$
\begin{aligned}
& \operatorname{Var}\left(\varepsilon_{i} \mid C\right)=\operatorname{Var}\left(\varepsilon_{i} \mid T\right)=\operatorname{Var}\left(\varepsilon_{i}\right) \\
& \operatorname{Cov}\left(\varepsilon_{i}, \varepsilon_{j} \mid C\right)=\operatorname{Cov}\left(\varepsilon_{i}, \varepsilon_{j} \mid T\right)=0 \\
& \operatorname{Corr}\left(\varepsilon_{i}, r_{j} \mid C\right)=\operatorname{Cov}\left(\varepsilon_{i}, r_{j} \mid T\right)=0
\end{aligned}
$$

Comparando as Equações 10 e 11, Corsetti, Pericoli e Sbracia (2005) afirmam que, se $\operatorname{Var}\left(\varepsilon_{\mathrm{i}}\right)$ e os parâmetros $\gamma_{i}^{2}$ e $\gamma_{j}^{2}$ são estáveis entre os períodos de tranquilidade e crise, o aumento na correlação entre os retornos dos países $\mathbf{j}$ e $\mathbf{i}$ será devido ao aumento mais que proporcional na variância do fator comum (Var $f$ ) em relação à variância dos fatores próprios do país em crise ( $\left.\operatorname{Var} \varepsilon_{\mathrm{j}}\right)$.

Esta estabilidade nos parâmetros $\gamma_{i}^{2}$ e $\gamma_{j}^{2}$ indica a manutenção dos processos geradores de retornos nos dois países (conforme Equações 2 e 3) e das relações existentes entre eles (conforme Equação 1), ou seja, indica que os efeitos sentidos em $\mathbf{i}$ dada uma crise em $\mathbf{j}$ se dão unicamente pela interdependência preexistente entre os países. Entretanto, o aumento na correlação de ambos também pode advir de um aumento nos parâmetros $\gamma_{i}^{2}$ e $\gamma_{j}^{2}$, caracterizando assim o efeito contágio (quebra das relações preexistentes). Neste trabalho, $\gamma_{i}^{2}$ e $\gamma_{j}^{2}$ serão chamados de cargas fatoriais por serem obtidas a partir de um modelo de Análise Fatorial. 
Para testar a presença de quebras estruturais nas cargas fatoriais do processo gerador dos retornos $(\gamma)$, o primeiro passo seria a especificação de um coeficiente de correlação em que seria aceita a hipótese nula de interdependência, ou seja, um coeficiente de correlação teórico ou esperado caso vigorasse apenas interdependência (e não contágio) entre os países (Corsetti, Pericoli, Sbracia, 2005).

Corsetti, Pericoli e Sbracia (2005) explicam a relação existente entre o coeficiente de correlação teórico proposto e a estabilidade das cargas fatoriais (sensibilidades) dos países ao risco sistêmico em eventos de crise. Tomando a transformada inversa da Equação 14 abaixo representada (que evidencia a medida de correlação teórica proposta pelos autores), os autores defendem que a proporção entre o risco próprio de um país $\mathbf{j}$ em crise e o risco sistêmico $\left(\lambda_{\mathrm{j}}\right.$, conforme Equação 15) deve ser alta durante a crise, o que levaria a um ajuste menor na correlação com os outros países (correlação esperada na crise crescendo menos). Assim, esse coeficiente esperado será testado contra o coeficiente de correlação observado sob o regime $\mathbf{C}$.

O coeficiente de correlação no período de crise sob a hipótese de interdependência $(\phi)$, ou seja, a medida teórica de interdependência, expressa na Equação 14, leva em conta a razão existente entre a variância do fator específico do país e do fator comum para os períodos de tranquilidade (Equação 15) e crise (Equação 16), do aumento da variância dos retornos do país de origem da crise (Equação 5) e da correlação observada no período de tranquilidade.

$$
\begin{gathered}
\phi\left(\lambda_{j}^{T}, \lambda_{j}^{C}, \delta, \rho^{T}\right) \equiv \rho^{T}\left[\left(\frac{1+\lambda_{j}^{T}}{1+\lambda_{j}^{C}}\right)^{2} \frac{1+\delta}{1+\left(\rho^{T}\right)^{2}\left[(1+\delta) \frac{1+\lambda_{j}^{T}}{1+\lambda_{j}^{C}}-1\right]\left(1+\lambda_{j}^{T}\right)}\right]^{1 / 2} \\
\lambda_{j}^{T}=\frac{\operatorname{Var}\left(\varepsilon_{j} \mid T\right)}{\gamma_{j}^{2} \operatorname{Var}(f \mid T)} \\
\lambda_{j}^{C}=\frac{\operatorname{Var}\left(\varepsilon_{j} \mid C\right)}{\gamma_{j}^{2} \operatorname{Var}(f \mid C)}
\end{gathered}
$$


Segundo Corsetti, Pericoli e Sbracia (2005, p.1183), "o coeficiente de correlação entre $r_{i}$ e $r_{j}$ durante a crise, denotado por $\rho^{C}$ e a medida teórica de interdependência, $\phi$, são os principais elementos para o teste de contágio baseado na análise das correlações. Se $\gamma_{i}$ e $\gamma_{j}$ não se alteram durante a crise, $\rho^{C}$ e $\phi$ irão coincidir. Mas, se existir o contágio na forma de um aumento na magnitude das cargas fatoriais, $\rho^{C}$ vai ser maior que $\phi . "$

Dessa forma, o teste de hipótese a ser realizado para verificar evidência do efeito contágio pode ser descrito pela Equação 17 a seguir, presente em Corsetti, Pericoli e Sbracia (2005, p. 1188). Se a hipótese nula não puder ser rejeitada, há indícios de interdependência entre os retornos dos países. Caso a hipótese nula seja rejeitada, há indícios de efeito contágio.

$$
\begin{aligned}
& H_{0}: \phi \geq \rho^{C} \\
& H_{1}: \phi<\rho^{C}
\end{aligned}
$$

Para a realização desse teste, será necessário modificar as correlações encontradas usando a transformação de Fisher, no intuito de poder trabalhar a distribuição das correlações a partir das características de uma distribuição normal (Corsetti, Pericoli, Sbracia, 2005). De acordo com os autores, há evidências de que a transformação z de Fisher é robusta a não normalidade dos dados, o que garante resultados satisfatórios à análise.

\section{Metodologia}

Conforme já especificado, o efeito contágio será testado empiricamente considerando os principais momentos de turbulências internacionais ocorridos desde a década de 1990 e até a primeira década do século XXI. Assim, os episódios de crises estudados serão a Crise da Ásia (1997-1998), Crise da Rússia (1998), Crise Brasileira (1999), Bolha da Internet (2000), Crise Argentina (2001), Ataque Terrorista de 11 de Setembro (2001), Crise Brasileira (2002) e Crise do Subprime (2007-2008). 
Como objetivo secundário, o estudo irá comparar o resultado obtido no teste empírico de Corsetti, Pericoli e Sbracia (2005) com os resultados dito enviesados que seriam obtidos no teste de Forbes e Rigobon (2002), no intuito de evidenciar a importância do comportamento heterocedástico da variância dos fatores próprios do país em crise na solução dos testes.

Conforme já adiantado na nota de rodapé 2 (página 563), a técnica de Análise Fatorial foi utilizada neste estudo para estimar o fator de risco sistêmico (score fatorial) que irá representar a componente comum dos retornos dos países da amostra. As cargas fatoriais de cada país neste score foram tomadas como as sensibilidades de cada país ao fator comum $(\gamma)$. Para a etapa de extração de fatores, foi utilizado o método de Análise dos Componentes Principais (ACP), sendo o número de fatores escolhido a priori (igual a 1). A rotação dos vetores foi realizada pelo método Varimax.

Conforme Corrar et al. (2007), os critérios utilizados para avaliar a adequação dos dados à Análise Fatorial foram os testes de esfericidade de Bartlett e KMO e a matriz de correlações de Pearson. De acordo com o teste de Bartlett, considerando 5\% de significância, rejeita-se a hipótese de que a matriz de correlações seja uma matriz identidade, ou seja, há correlações significativas que indicam a adequação da análise fatorial. Já o teste KMO apresentou estatística de teste de 0,908. Considerando as interpretações do teste sugeridas por Fávero et al. (2009), verifica-se que há uma adequação muito boa dos dados à técnica Fatorial. De acordo com a matriz de correlações de Pearson, considerando um nível de significância de 5\%, todos os países da amostra apresentaram retornos significativamente correlacionados. Assim, a matriz de correlações também indicou uma boa adequação da Análise Fatorial aos dados. Esta adequação foi garantida após a exclusão de países que não apresentavam correlações estatisticamente diferentes de zero com a maioria dos outros países da amostra.

Após a estimação do fator de risco sistêmico e das cargas fatoriais, essas estimativas foram substituídas nas Equações 2 e 3 no intuito de calcular a componente própria dos retornos dos países. A Tabela 1, abaixo, apresenta as taxas livres de risco selecionadas para a composição do vetor $\alpha$, evidenciando os índices utilizados com seus respectivos tickers da Bloomberg e datas de início das séries. 
O índice da Tailândia está destacado no intuito de demonstrar o motivo pelo qual se optou pela exclusão do país da amostra (a data de início do índice é julho de 2005 e a data de início das análises neste trabalho é 01/06/1996. Caso uma extrapolação do índice fosse feita, poderia levar a vieses ou conclusões errôneas tanto a respeito do próprio país, quanto contaminar a composição dos fatores e cargas fatoriais de toda a amostra).

Tabela 1 - Índices utilizados como proxy para as taxas livres de risco

\begin{tabular}{|c|c|c|}
\hline Países & Ticker Bloomberg & Data de Início da Série do índice \\
\hline AFRSUL & SARPRT & abr/98 \\
\hline ARG & ARPPAC & jan/90 \\
\hline AUS & RBATCTR & jev/90 $/ 90$ \\
\hline BRA & BZSELICA & dez/92 \\
\hline CAN & CABROVER & jun/95 \\
\hline CHI & CHOVCHOV & abr/95 \\
\hline COL & COMMINTB & jan/96 \\
\hline ESP & ECBRON & fev/90 \\
\hline EUA & FDFD & jan/96 \\
\hline FRA & ECBRON & set/95 \\
\hline HON & HIHDON & jan/96 \\
\hline ITA & ECBRON & jan/93 \\
\hline JAP & MUTSCALM & nov/95 \\
\hline RUS & MOIBO01D & jun/05 \\
\hline TAl & BOATTHON & fev/90 \\
\hline TWN & NTON & \\
\hline
\end{tabular}

Fonte: Bloomberg.

Os dados necessários à análise foram levantados a partir da base de dados da Bloomberg, tendo sido escolhido o retorno nominal do principal índice da bolsa de valores de cada país como representativo do 'retorno financeiro' da economia daquele país. De acordo com testes de robustez dos resultados realizados por Corsetti, Pericoli e Sbracia (2005), não houve diferenças significativas entre os testes de efeito contágio utilizando índices dolarizados e em moedas locais, uma vez utilizados os retornos logarítmicos desses. Assim, optou-se por utilizar o retorno dos índices em moeda local e realizar testes de robustez com os índices dolarizados. ${ }^{3}$

3 Utilizou-se como estimativa de variação cambial o diferencial entre as inflações domésticas de cada país e a inflação americana. 
A escolha dos países para compor a amostra de estudo seguiu cinco critérios: (a) média do volume de negócios na principal bolsa de valores do país entre 01/01/2009 e 17/08/2010, (b) origem das crises financeiras a serem estudadas, (c) importância econômica dos países no cenário internacional, (d) adequação dos dados à técnica estatística a ser aplicada e (e) participação efetiva na composição do fator de risco sistêmico.

A Tabela 2, abaixo, apresenta os quinze países escolhidos a partir dos critérios relacionados acima, seus respectivos índices analisados, assim como seus tickers e volume de negócios. Em destaque estão os países considerados origens das crises financeiras analisadas. Optouse pela escolha máxima de cinco países por continente no intuito de captar indícios do efeito contágio em todas as regiões do mundo, não se limitando aos efeitos em determinada região ou bloco econômico, mas sim abranger as diversas consequências que as crises financeiras poderiam apresentar.

Tabela 2 - Listagem dos 15 países escolhidos para compor a amostra, seus respectivos índices, tickers e volume de negócios

\begin{tabular}{|c|c|c|c|c|c|}
\hline CONTINENTES & PAÍSES & ÍNDICES (Bloomberg) & TICKERS (Bloomberg) & $\begin{array}{l}\text { VOLUME DE } \\
\text { NEGÓCIOS }\end{array}$ & $\begin{array}{l}\text { ANO DA } \\
\text { CRISE }\end{array}$ \\
\hline \multirow{3}{*}{ ÁSIA } & HONG KONG & HANG SENG INDEX & HIS Index & $2.068 .695 .890,87$ & 1997 \\
\hline & TAIWAN & TAIWAN TAIEX INDEX & TWSE Index & $3.842 .983 .644,54$ & \\
\hline & JAPAO & NIKKEI 225 & NKY Index & $1.499 .006 .086,64$ & \\
\hline \multirow{4}{*}{$\begin{array}{l}\text { AMÉRICA } \\
\text { LATINA }\end{array}$} & ARGENTINA & $\begin{array}{l}\text { ARGENTINA MERVAL } \\
\text { INDEX }\end{array}$ & MERVAL Index & $7.131 .877,46$ & 2001 \\
\hline & BRASIL & BRAZIL BOVESPA INDEX & IBOV Index & $181.069 .905,61$ & 1999,2002 \\
\hline & CHILE & $\begin{array}{l}\text { CHILE STOCK MKT } \\
\text { SELECT }\end{array}$ & IPSA Index & $434.051 .404,82$ & \\
\hline & COLÔMBIA & IGBC GENERAL INDEX & IGBC Index & $769.858 .244,92$ & \\
\hline \multirow{2}{*}{$\begin{array}{l}\text { AMÉRICA DO } \\
\text { NORTE }\end{array}$} & EUA & S\&P 500 INDEX & SPX Index & $1.112 .013 .840,23$ & $\begin{array}{c}2000,2001 \mathrm{e} \\
2007\end{array}$ \\
\hline & CANADA & $\begin{array}{l}\text { S\&P/TSX COMPOSITE } \\
\text { INDEX }\end{array}$ & SPTSX Index & $199.361 .207,74$ & \\
\hline OCEANIA & AUSTRALIA & S\&P/ASX 200 INDEX & AS51 Index & $1.065 .685 .954,64$ & \\
\hline \multirow{4}{*}{ EUROPA } & RUSSIA & $\begin{array}{l}\text { RUSSIAN RTS } \\
\text { INDEX \$ }\end{array}$ & RTSI\$ Index & $1.138 .069 .397,55$ & 1998 \\
\hline & ITALIA & FTSE MIB INDEX & FTSEMIB Index & $777.676 .818,87$ & \\
\hline & ESPANHA & IBEX 35 INDEX & IBEX Index & $353.949 .980,11$ & \\
\hline & FRANCA & CAC 40 INDEX & CAC Index & $146.866 .291,47$ & \\
\hline AFRICA & $\begin{array}{l}\text { AFRICA DO } \\
\text { SUL }\end{array}$ & $\begin{array}{c}\text { FTSE/JSE AFRICA ALL } \\
\text { SHR }\end{array}$ & JALSH Index & $210.856 .038,75$ & \\
\hline
\end{tabular}

Fonte: elaboração própria a partir de dados da Bloomberg. 
Os dados dos retornos das bolsas dos países foram trabalhados no software estatístico SPSS. O período amostral considerado para a composição do fator comum é de 01/06/1996 (início do período de tranquilidade da crise da Ásia) a 17/03/2009 (final do período inicial de crise do Subprime). A amostra compreende valores diários dos índices das bolsas, transformados em retornos logarítmicos utilizando a média móvel de dois dias, com o intuito de captar diferenças de fuso horário entre os países (Billio e Caporin, 2010).

A maioria das datas de início das crises foi escolhida de acordo com a primeira queda do índice das bolsas de valores dos países e suportada pela literatura. Quando havia eventos pontuais não relacionados ao mercado de capitais, como data de moratórias e abandono de sistema cambial, optou-se por considerar como início da crise a data da primeira queda do índice de mercado de capitais do país próximo ao período indicado pela mídia como de turbulência, uma vez que esses eventos pontuais são considerados como consequências de crises iniciadas anteriormente. As datas desses eventos pontuais foram utilizadas posteriormente no intuito de realizar testes de robustez dos resultados. As datas de final da crise foram baseadas na literatura existente e na recuperação do nível do índice à estabilidade. $\mathrm{Na}$ Tabela 3 estão descritas as datas de início e fim dos períodos de tranquilidade e crise para cada evento a ser analisado; na Tabela 3.1 estão as datas alternativas utilizadas para testes de robustez.

Tabela 3 - Datas de início e fim dos períodos de tranquilidade e crise dos eventos

\begin{tabular}{|c|c|c|c|c|}
\hline Crise & País de Origem & Marco de Início da Crise & $\begin{array}{l}\text { Período de } \\
\text { Tranquilidade }\end{array}$ & $\begin{array}{l}\text { Período } \\
\text { de Crise }\end{array}$ \\
\hline Crise da Ásia & Hong Kong & $\begin{array}{c}\text { De acordo com Forbes e } \\
\text { Rigobon (2002) }\end{array}$ & $\begin{array}{c}01 / 06 / 1996 \mathrm{a} \\
16 / 10 / 1997\end{array}$ & $\begin{array}{c}17 / 10 / 1997 a \\
05 / 03 / 1998\end{array}$ \\
\hline Crise da Rússia & Rússia & $\begin{array}{l}\text { Primeira queda do índice } \\
\text { da bolsa no período }\end{array}$ & $\begin{array}{c}01 / 01 / 1998 a \\
26 / 07 / 1998\end{array}$ & $\begin{array}{c}27 / 07 / 1998 a \\
16 / 09 / 1999\end{array}$ \\
\hline Crise Brasileira de 1999 & Brasil & $\begin{array}{l}\text { De acordo com Lobão } \\
(2007)\end{array}$ & $\begin{array}{c}20 / 09 / 1998 a \\
03 / 01 / 1999\end{array}$ & $\begin{array}{c}\text { 04/01/1999a } \\
15 / 03 / 1999\end{array}$ \\
\hline Crise da Bolha da Internet & EUA & $\begin{array}{l}\text { Primeira queda do índice } \\
\text { NASDAQ no período }\end{array}$ & $\begin{array}{c}04 / 01 / 1999 a \\
10 / 03 / 2000\end{array}$ & $\begin{array}{c}11 / 03 / 2000 a \\
23 / 04 / 2001\end{array}$ \\
\hline 11 de Setembro & EUA & $\begin{array}{l}\text { Ataque terrorista ao } \\
\text { World Trade Center }\end{array}$ & $\begin{array}{c}25 / 04 / 2001 \mathrm{a} \\
10 / 09 / 2001\end{array}$ & $\begin{array}{c}11 / 09 / 2001 \mathrm{a} \\
08 / 04 / 2003\end{array}$ \\
\hline Crise da Argentina & Argentina & $\begin{array}{l}\text { Primeira queda do índice } \\
\text { da bolsa no período }\end{array}$ & $\begin{array}{l}01 / 01 / 2001 \mathrm{a} \\
11 / 07 / 2001\end{array}$ & $\begin{array}{c}12 / 07 / 2001 \text { a } \\
24 / 05 / 2002\end{array}$ \\
\hline Crise Brasileira de 2002 & Brasil & $\begin{array}{l}\text { Primeira queda do índice } \\
\text { da bolsa no período }\end{array}$ & $\begin{array}{l}\text { 01/01/2001 a } \\
12 / 09 / 2001\end{array}$ & $\begin{array}{c}13 / 09 / 2001 \mathrm{a} \\
02 / 02 / 2003\end{array}$ \\
\hline Crise do Subprime & EUA & $\begin{array}{l}\text { Primeira queda do índice } \\
\text { da bolsa no período }\end{array}$ & $\begin{array}{l}09 / 10 / 2005 a \\
25 / 07 / 2007\end{array}$ & $\begin{array}{c}26 / 07 / 2007 a \\
17 / 03 / 2009 \\
\end{array}$ \\
\hline
\end{tabular}

Fonte: elaboração própria a partir de dados da Bloomberg. 
Tabela 3.1 - Tabela com períodos de tranquilidade e crise no teste de robustez

\begin{tabular}{|c|c|c|c|c|c|}
\hline \multirow{2}{*}{ Crise } & \multirow{2}{*}{ País de Origem } & \multirow{2}{*}{ Marco de Início da Crise } & \multirow{2}{*}{ Teste de Robustez } & \multicolumn{2}{|c|}{ Teste de Robustez } \\
\hline & & & & $\mathrm{T}$ & C \\
\hline Crise da Ásia & Hong Kong & $\begin{array}{l}\text { De acordo com Forbes e } \\
\text { Rigobon (2002) }\end{array}$ & $\begin{array}{l}\text { Desvalorização da } \\
\text { moeda tailandesa } \\
\text { (baht) }\end{array}$ & $\begin{array}{l}\text { 01/07/1996 } \\
\text { a 01/07/1997 }\end{array}$ & $\begin{array}{l}\text { 02/07/1997 } \\
\text { a 17/11/1997 }\end{array}$ \\
\hline Crise da Rússia & Rússia & $\begin{array}{l}\text { Primeira queda do índice } \\
\text { da bolsa no período }\end{array}$ & Moratória & $\begin{array}{c}18 / 11 / 1997 \\
\text { a } 16 / 08 / 1998\end{array}$ & $\begin{array}{l}17 / 08 / 1998 \\
\text { a 01/06/1999 }\end{array}$ \\
\hline $\begin{array}{l}\text { Crise Brasileira } \\
\text { de } 1999\end{array}$ & Brasil & $\begin{array}{l}\text { De acordo com Lobão } \\
\text { (2007) }\end{array}$ & $\begin{array}{l}\text { Abandono do } \\
\text { câmbio semi-fixo }\end{array}$ & $\begin{array}{l}\text { 01/09/1998 } \\
\text { a 31/01/1999 }\end{array}$ & $\begin{array}{c}\text { 01/02/1999 } \\
\text { a 15/03/1999 }\end{array}$ \\
\hline $\begin{array}{l}\text { Crise da Bolha da } \\
\text { Internet }\end{array}$ & EUA & $\begin{array}{l}\text { Primeira queda do índice } \\
\text { NASDAQ no período }\end{array}$ & $\begin{array}{l}\text { Primeira queda do } \\
\text { índice NASDAQ no } \\
\text { período }\end{array}$ & $\begin{array}{l}10 / 04 / 1999 \\
\text { a 10/03/2000 }\end{array}$ & $\begin{array}{l}11 / 03 / 2000 \\
\text { a } 31 / 12 / 2000\end{array}$ \\
\hline 11 de Setembro & EUA & $\begin{array}{c}\text { Ataque terrorista ao World } \\
\text { Trade Center }\end{array}$ & $\begin{array}{l}\text { Ataque terrorista ao } \\
\text { World Trade Center }\end{array}$ & $\begin{array}{l}10 / 08 / 2001 \\
\text { a } 10 / 09 / 2001\end{array}$ & $\begin{array}{c}11 / 09 / 2001 \\
\text { a } 01 / 06 / 2003\end{array}$ \\
\hline Crise da Argentina & Argentina & $\begin{array}{l}\text { Primeira queda do índice } \\
\text { da bolsa no período }\end{array}$ & Moratória & $\begin{array}{l}\text { 22/11/2001 } \\
\text { a 22/12/2001 }\end{array}$ & $\begin{array}{l}\text { 23/12/2001 } \\
\text { a 24/05/2002 }\end{array}$ \\
\hline $\begin{array}{l}\text { Crise Brasileira } \\
\text { de } 2002\end{array}$ & Brasil & $\begin{array}{l}\text { Primeira queda do índice } \\
\text { da bolsa no período }\end{array}$ & $\begin{array}{l}\text { Início do governo } \\
\text { Lula }\end{array}$ & $\begin{array}{c}31 / 11 / 2001 \\
\text { a } 31 / 12 / 2001\end{array}$ & $\begin{array}{l}01 / 01 / 2002 \\
\text { a } 01 / 10 / 2002\end{array}$ \\
\hline Crise do Subprime & EUA & $\begin{array}{l}\text { Primeira queda do índice } \\
\text { da bolsa no período }\end{array}$ & $\begin{array}{l}\text { Período em que a } \\
\text { crise do Subprime } \\
\text { atinge a bolsa de NY }\end{array}$ & $\begin{array}{l}30 / 06 / 2006 \\
\text { a 30/06/2007 }\end{array}$ & $\begin{array}{l}\text { 01/07/2007 } \\
\text { a 17/03/2009 }\end{array}$ \\
\hline
\end{tabular}

Fonte: elaboração própria a partir de dados da Bloomberg.

\section{Resultados}

Por meio da aplicação das metodologias de Forbes e Rigobon (2002) e Corsetti, Pericoli e Sbracia (2005), foi elaborada a Tabela 4, onde estão consolidadas as análises. Verifica-se que, conforme esperado, o teste de Forbes e Rigobon (2002) não trouxe à tona nenhum indício de contágio decorrente de nenhuma das oito crises financeiras analisadas. De acordo com os próprios autores, o ajuste feito nos coeficientes de correlação observados extrai a componente heterocedástica dos retornos dos países, indicando que, apesar de haver incremento nas correlações entre os períodos de tranquilidade e crise, este é esperado e não passa da manutenção da relação de interdependência entre as economias. Na visão de Corsetti, Pericoli e Sbracia (2005), o ajuste sugerido por Forbes e Rigobon (2002) é enviesado em rejeitar indícios de efeito contágio. Dessa forma, a aplicação da metodologia sugerida por Corsetti, Pericoli e Sbracia (2005) trouxe indícios de oito casos de efeito contágio durante a crise da Asia, seis após o ataque terrorista de 11 de setembro de 2001, quatro durante a crise brasileira de 1999, três durante a bolha da Internet de 2000 
e dois durante a crise do Subprime. Para as crises russa, argentina e brasileira de 2002 não houve indícios de efeito contágio. No Anexo são apresentadas as cargas fatoriais e as principais medidas utilizadas, para cada crise, tanto no teste de Forbes e Rigobon (2002) quanto no teste de Corsetti, Pericoli e Sbracia (2005). Entre essas medidas estão: variância dos retornos dos países origens das crises nos períodos de tranquilidade e crise, assim como as variâncias dos fatores próprios e sistêmico também nos dois momentos. Na Tabela 5 podem ser encontrados os valores de correlação ajustados utilizados na metodologia de Forbes e Rigobon (2002), assim como os coeficientes de correlação teórico e observado utilizados na metodologia de Corsetti, Pericoli e Sbracia (2005).

Tabela 4 - Tabela resumo dos resultados das aplicações das metodologias de Forbes e Rigobon (2002) e de Corsetti, Pericoli e Sbracia (2005)

\begin{tabular}{|c|c|c|c|}
\hline \multicolumn{4}{|c|}{ Tabela Resumo } \\
\hline \multirow[t]{2}{*}{ Crises } & \multicolumn{2}{|c|}{ Número de países com indícios de contágio } & \multirow{2}{*}{ Países contagiados } \\
\hline & Forbes e Rigobon (2002) & Corsetti, Pericoli e Sbracia (2005) & \\
\hline Crise da Ásia (1997) & 0 & 8 & $\begin{array}{l}\text { África do Sul, Austrália, Canadá, } \\
\text { Chile, Espanha, França, Japão } \\
\text { e Rússia }\end{array}$ \\
\hline Crise da Rússia (1998) & 0 & 0 & \\
\hline Crise Brasileira (1999) & 0 & 4 & Argentina, Canadá, Chile e EUA \\
\hline Bolha da Internet (2000) & 0 & 3 & $\begin{array}{l}\text { África do Sul, Argentina e } \\
\text { Canadá }\end{array}$ \\
\hline 11 de setembro (2001) & 0 & 6 & $\begin{array}{l}\text { Austrália, Brasil, Canadá, Chile, } \\
\text { Espanha e França }\end{array}$ \\
\hline Crise Argentina (2001) & 0 & 0 & \\
\hline Crise Brasileira (2002) & 0 & 0 & \\
\hline Crise do Subprime & 0 & 2 & Brasil e Canadá \\
\hline
\end{tabular}

Fonte: elaboração própria. 


\begin{tabular}{|c|c|c|c|c|c|c|c|c|c|c|c|c|c|c|c|c|}
\hline & 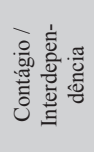 & 0 & - & 0 & - & 0 & 0 & - & 0 & - & 0 & & - & 0 & 0 & - \\
\hline \multirow{9}{*}{ 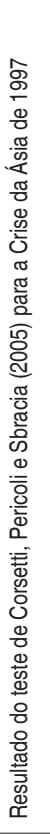 } & 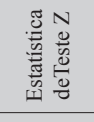 & $\begin{array}{l}\text { مू } \\
0 \\
0 \\
0\end{array}$ & 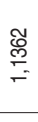 & 总 & 尽 & 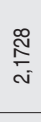 & $\begin{array}{l}\mathbb{J} \\
\stackrel{8}{\circ} \\
\text { i }\end{array}$ & 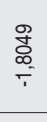 & $\begin{array}{l}\mathscr{8} \\
\stackrel{5}{+} \\
\text { ల) }\end{array}$ & 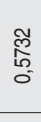 & i⿱ ָָ & & 홍 & స్̃ & $\begin{array}{l}\frac{9}{9} \\
\substack{\infty \\
\infty \\
\mathbb{f}}\end{array}$ & \\
\hline & 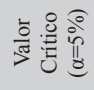 & ঃి & $\begin{array}{l}\stackrel{8}{\circ} \\
\stackrel{-}{-}\end{array}$ & $\begin{array}{l}\stackrel{8}{\circ} \\
\stackrel{-}{-}\end{array}$ & $\begin{array}{l}\stackrel{8}{\circ} \\
:\end{array}$ & : & $\begin{array}{l}\stackrel{8}{\circ} \\
\stackrel{-}{-}\end{array}$ & 。্̊ & $\stackrel{\circ}{\circ}$ & $\stackrel{\circ}{\circ}$ & $\begin{array}{l}\stackrel{8}{\circ} \\
\stackrel{\circ}{-}\end{array}$ & & 怘 & 응 & ঃ & 욤 \\
\hline & ¿ & $\underset{\frac{1}{5}}{\stackrel{5}{0}}$ & 㝵 & $\frac{18}{\frac{1}{0}}$ & $\frac{\stackrel{8}{5}}{\underbrace{}_{0}}$ & $\frac{\stackrel{18}{+}}{\frac{5}{0}}$ & $\frac{8}{\frac{8}{5}}$ & $\underset{\frac{8}{5}}{\stackrel{5}{0}}$ & $\underset{\frac{8}{5}}{\stackrel{5}{0}}$ & $\frac{18}{\frac{8}{5}}$ & $\frac{⿱ 8}{5}$ & & $\underset{\stackrel{8}{+}}{\stackrel{5}{5}}$ & $\frac{\text { 年 }}{\frac{5}{0}}$ & $\frac{\frac{8}{5}}{\frac{8}{0}}$ & $\frac{8}{\stackrel{8}{0}}$ \\
\hline & 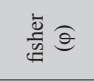 & $\frac{\bar{c}}{\frac{5}{0}}$ & $\frac{0}{\frac{9}{0}}$ & $\begin{array}{l}\frac{\infty}{0} \\
\frac{0}{0}\end{array}$ & $\frac{\frac{9}{0}}{0}$ & $\begin{array}{l}\text { to } \\
\frac{0}{0} \\
0\end{array}$ & $\begin{array}{l}8 \\
\stackrel{8}{0} \\
\\
0\end{array}$ & $\begin{array}{l}\text { ஜू. } \\
\text { : } \\
0\end{array}$ & $\begin{array}{l}\stackrel{0}{0} \\
0 \\
0\end{array}$ & $\frac{\mathscr{8}}{\frac{8}{0}}$ & $\frac{\overline{0}}{0}$ & & 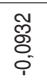 & $\begin{array}{l}\circ \\
0 \\
0\end{array}$ & $\begin{array}{l}\frac{8}{0} \\
\frac{0}{0}\end{array}$ & $\frac{8}{0}$ \\
\hline & 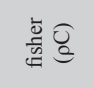 & $\begin{array}{l}\mathscr{0} \\
\& \\
\& \\
0 \\
0\end{array}$ & 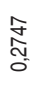 & 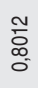 & 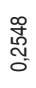 & $\begin{array}{l}\frac{0}{0} \\
\frac{7}{0} \\
0\end{array}$ & $\begin{array}{l}\frac{\pi}{0} \\
\dot{6} \\
0\end{array}$ & $\frac{d}{\frac{d}{0}}$ & $\begin{array}{l}\text { 응 } \\
\text { 용 }\end{array}$ & 욤 & 先 & & 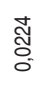 & 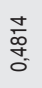 & 兽 & $\begin{array}{l}\hat{0} \\
\text { o } \\
0\end{array}$ \\
\hline & $\theta$ & $\underset{0}{\stackrel{t}{t}}$ & $\frac{\mathscr{8}}{\frac{8}{\sigma}}$ & $\begin{array}{l}\frac{\mathrm{d}}{6} \\
\frac{6}{\circ}\end{array}$ & $\frac{9}{\frac{9}{0}}$ & $\begin{array}{l}\text { Fै } \\
\frac{0}{0}\end{array}$ & $\frac{\stackrel{\circ}{\circ}}{0}$ & $\begin{array}{l}\text { ̊̊ } \\
\text { : }\end{array}$ & $\frac{\bar{E}}{0}$ & $\frac{\pi}{\frac{8}{8}}$ & $\begin{array}{l}\text { 영 } \\
\text { 응 }\end{array}$ & & $\begin{array}{l}\text { \% } \\
\text { o. } \\
\text { i. }\end{array}$ & $\begin{array}{l}\stackrel{0}{\circ} \\
\frac{0}{0}\end{array}$ & $\frac{\mathbb{0}}{0}$ & $\frac{\stackrel{8}{8}}{\frac{8}{0}}$ \\
\hline & ¿ & $\begin{array}{l}\infty \\
\vdots \\
0 \\
0\end{array}$ & 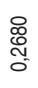 & $\begin{array}{l}\text { f } \\
\text { ¿ } \\
0\end{array}$ & $\begin{array}{l}\text { 索 } \\
\text { ․ }\end{array}$ & $\begin{array}{l}\widetilde{్} \\
\widetilde{్} \\
\text { o. }\end{array}$ & $\frac{m}{\underline{m}}$ & $\frac{\stackrel{8}{\circ}}{\frac{\rho}{0}}$ & $\begin{array}{l}\text { ô } \\
0 \\
0 \\
0\end{array}$ & $\begin{array}{l}\infty \\
\stackrel{\infty}{0} \\
\text { đิ }\end{array}$ & $\begin{array}{l}\widehat{0} \\
\text { : } \\
\text { o. }\end{array}$ & & 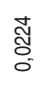 & 寺 & $\frac{8}{\frac{8}{0}}$ & $\begin{array}{l}\text { त్ } \\
\text { ळ. } \\
0\end{array}$ \\
\hline & $t_{2}$ & $\begin{array}{l}\text { o. } \\
\text { 足 } \\
0\end{array}$ & 兽 & $\stackrel{\bar{\infty}}{\bar{c}}$ & $\frac{8}{\circ}$ & $\frac{\infty}{\stackrel{\infty}{N}}$ & $\begin{array}{l}\hat{0} \\
\stackrel{0}{\circ} \\
0 \\
0\end{array}$ & $\begin{array}{l}\hat{0} \\
\text { o. } \\
0\end{array}$ & 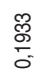 & 怘 & 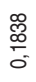 & & 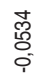 & $\begin{array}{l}8 \\
\text { مิ } \\
\text { N. }\end{array}$ & 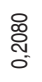 & $\begin{array}{l}\hat{0} \\
\stackrel{N}{0} \\
0\end{array}$ \\
\hline & $\stackrel{\mathscr{\#}}{\dddot{\#}}$ & 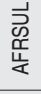 & 品 & $\stackrel{0}{<}$ & 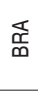 & 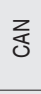 & $\overline{\bar{S}}$ & $\overrightarrow{\mathrm{O}}$ & $\begin{array}{l}\text { 品 } \\
\text {. }\end{array}$ & 胥 & $\underset{\mathbb{4}}{\mathbb{4}}$ & 오 & $\Xi$ & 号 & 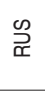 & $\sum_{k}$ \\
\hline \multirow{8}{*}{ 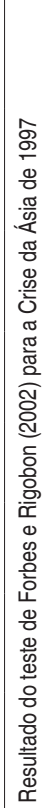 } & 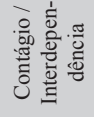 & - & - & - & - & - & - & - & - & - & - & & - & - & - & - \\
\hline & 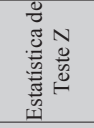 & 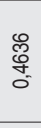 & $\begin{array}{l}\text { 总 } \\
\text { o } \\
\end{array}$ & 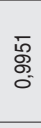 & $\begin{array}{l}\frac{7}{0} \\
\frac{0}{0} \\
0\end{array}$ & 胥 & $\begin{array}{l}\frac{1}{4} \\
0 \\
0 \\
0\end{array}$ & $\begin{array}{l}\text { 畩 } \\
\text { o }\end{array}$ & $\begin{array}{l}\text { 吕 } \\
\text { ه్ } \\
0\end{array}$ & $\begin{array}{l}\stackrel{8}{\circ} \\
\frac{m}{0}\end{array}$ & 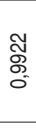 & & $\begin{array}{l}\text { 蒿 } \\
\text { O. }\end{array}$ & $\begin{array}{l}\text { O్ } \\
\text { స్. }\end{array}$ & $\begin{array}{l}\frac{N}{0} \\
\stackrel{0}{0} \\
0\end{array}$ & 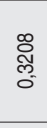 \\
\hline & 흘 & 욤 & 용 & 용 & 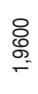 & \& & 兽 & : & 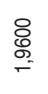 & 용 & 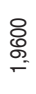 & & 兽 & $\begin{array}{l}\text { o } \\
\stackrel{-}{\circ}\end{array}$ & 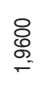 & \&: \\
\hline & 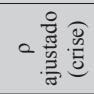 & 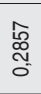 & $\begin{array}{l}\bar{\alpha} \\
\text { ¿o } \\
0 \\
0\end{array}$ & $\begin{array}{l}\text { ồ } \\
\text { Ò } \\
0\end{array}$ & $\begin{array}{l}\text { ô } \\
\text { : } \\
0\end{array}$ & & $\frac{\mathscr{\%}}{\frac{\mathscr{g}}{0}}$ & $\begin{array}{l}\frac{\infty}{0} \\
\frac{0}{0} \\
0\end{array}$ & $\begin{array}{l}\stackrel{2}{0} \\
\stackrel{0}{0} \\
0\end{array}$ & $\begin{array}{l}\text { 今े } \\
\text { ष्. } \\
0\end{array}$ & \begin{tabular}{l} 
N \\
\multirow{N}{N}{} \\
O
\end{tabular} & & $\begin{array}{l}\infty \\
\stackrel{\infty}{0} \\
0\end{array}$ & $\begin{array}{l}\overline{0} \\
0 \\
0 \\
0\end{array}$ & 胥 & 惫 \\
\hline & $\bigcup_{a}$ & $\begin{array}{l}\infty \\
\stackrel{0}{0} \\
0\end{array}$ & 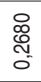 & $\begin{array}{l}\text { fे } \\
\text { : } \\
0\end{array}$ & 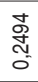 & $\begin{array}{l}\text { జ్ } \\
\text { ల్ } \\
0\end{array}$ & $\frac{m}{p}$ & 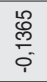 & $\begin{array}{l}\text { o. } \\
\text { o. } \\
0\end{array}$ & 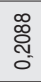 & $\begin{array}{l}\text { 心్ల } \\
\text { : } \\
0\end{array}$ & & 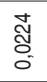 & 告 & $\frac{\mathscr{g}}{\frac{8}{0}}$ & $\begin{array}{l}\text { त్ } \\
\text { ल. } \\
\text { o }\end{array}$ \\
\hline & 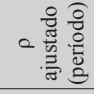 & 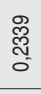 & $\begin{array}{l}\tilde{0} \\
\stackrel{0}{0} \\
0 \\
0\end{array}$ & $\frac{\text { o }}{\frac{\sigma}{0}}$ & $\begin{array}{l}\text { ơ } \\
\stackrel{0}{0} \\
0\end{array}$ & & $\begin{array}{l}0 \\
\stackrel{0}{\circ} \\
\circ\end{array}$ & $\begin{array}{l}\frac{9}{5} \\
\stackrel{0}{0} \\
0\end{array}$ & $\frac{\infty}{\circ}$ & $\begin{array}{l}\overline{0} \\
\text { 용 } \\
0\end{array}$ & $\frac{⿱ 0}{\frac{m}{0}}$ & & 옹 & 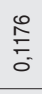 & $\frac{\stackrel{\mathscr{N}}{\Im}}{0}$ & $\begin{array}{l}\frac{1}{\hat{0}} \\
0 \\
0\end{array}$ \\
\hline & 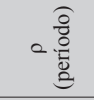 & స్ & 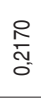 & 寽 & $\begin{array}{l}\stackrel{0}{\circ} \\
\stackrel{\Xi}{-5} \\
\end{array}$ & 0 & $\begin{array}{l}\overline{\mathrm{S}} \\
\text { o. }\end{array}$ & 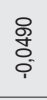 & 氶 & $\frac{0}{0}$ & 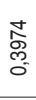 & & 형 & $\begin{array}{l}\mathscr{0} \\
\text { o } \\
0 \\
0\end{array}$ & 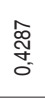 & $\begin{array}{l}\text { o } \\
\text { d̦ } \\
\text { d. }\end{array}$ \\
\hline & $\stackrel{n}{\tilde{\Xi}}$ & $\begin{array}{l}\text { 岕 } \\
\text { 䍃 }\end{array}$ & 品 & $\stackrel{N}{z}$ & 㟧 & zoc & 퐁 & $\overrightarrow{\mathrm{O}}$ & 号 & 豈 & 离 & 오 & $\Xi$ & $\frac{0}{5}$ & 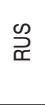 & $\sum_{k}$ \\
\hline
\end{tabular}




\begin{tabular}{|c|c|c|c|c|c|c|c|c|c|c|c|c|c|c|c|c|}
\hline \multirow{10}{*}{ 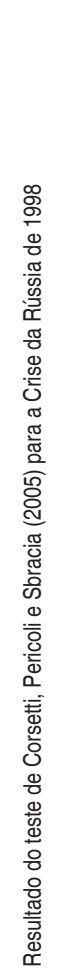 } & 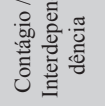 & - & - & - & - & - & - & - & - & - & - & - & - & - & & - \\
\hline & 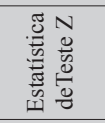 & ֶֻ & 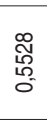 & 邫 & 趸 & 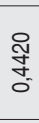 & 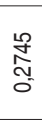 & $\frac{\bar{E}}{\underline{N}}$ & 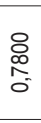 & $\begin{array}{l}0 \\
\stackrel{0}{0} \\
\stackrel{0}{0} \\
1\end{array}$ & $\begin{array}{l}\text { 总 } \\
=\end{array}$ & $\begin{array}{l}\frac{10}{0} \\
60 \\
0 \\
0\end{array}$ & 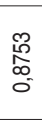 & $\frac{\text { סू }}{\circ}$ & & 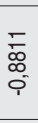 \\
\hline & 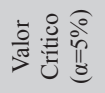 & $\begin{array}{l}\stackrel{8}{\circ} \\
\stackrel{-}{-}\end{array}$ & \&্口 & $\begin{array}{l}8 \\
\stackrel{8}{-}\end{array}$ & $\stackrel{\stackrel{8}{\circ}}{\stackrel{-}{-}}$ & $\begin{array}{l}8 \\
\text { : } \\
-\end{array}$ & $\begin{array}{l}8 \\
\text { : } \\
-\end{array}$ & $\begin{array}{l}8 \\
\text { : } \\
-\end{array}$ & $\begin{array}{l}\stackrel{8}{\circ} \\
\stackrel{-}{-}\end{array}$ & $\stackrel{8}{\circ}$ & $\begin{array}{l}\text { \&. } \\
\text { : }\end{array}$ & ষ্ণ & $\begin{array}{l}8 \\
8 \\
:\end{array}$ & ه্: & & $\begin{array}{l}8 \\
\stackrel{8}{-}\end{array}$ \\
\hline & $\tilde{\sigma}$ & $\begin{array}{l}\stackrel{\infty}{\infty} \\
\frac{\infty}{0} \\
-\end{array}$ & $\begin{array}{l}\stackrel{\infty}{\infty} \\
\frac{\infty}{0} \\
0\end{array}$ & 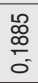 & $\begin{array}{l}\stackrel{\infty}{\infty} \\
\frac{\infty}{0} \\
0\end{array}$ & $\begin{array}{l}\stackrel{\infty}{\infty} \\
\frac{\infty}{0} \\
\end{array}$ & 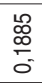 & $\begin{array}{l}\mathscr{\infty} \\
\stackrel{\infty}{0} \\
\frac{0}{0}\end{array}$ & $\begin{array}{l}\stackrel{\infty}{\infty} \\
\cong \\
0\end{array}$ & $\begin{array}{l}\stackrel{\infty}{\infty} \\
\frac{\infty}{0} \\
-\end{array}$ & 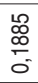 & $\begin{array}{l}\infty \\
\infty \\
\frac{\infty}{0}\end{array}$ & $\begin{array}{l}\mathscr{L} \\
\infty \\
\frac{\infty}{0} \\
\end{array}$ & 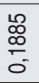 & & $\begin{array}{l}\mathscr{\infty} \\
\stackrel{\infty}{0} \\
\frac{0}{0}\end{array}$ \\
\hline & $\stackrel{\bar{\Xi}}{\bar{n}} \widehat{\varrho}$ & $\begin{array}{l}\mathscr{\infty} \\
\frac{\infty}{0} \\
0\end{array}$ & $\frac{}{\frac{0}{0}}$ & 总 & $\begin{array}{l}\bar{\alpha} \\
\bar{\infty} \\
\overline{-}\end{array}$ & $\begin{array}{l}\frac{\infty}{\infty} \\
\frac{\infty}{5}\end{array}$ & $\begin{array}{l}\frac{0}{0} \\
\frac{0}{0} \\
\end{array}$ & ס্ & 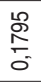 & $\begin{array}{l}\stackrel{0}{2} \\
\frac{1}{0} \\
0\end{array}$ & $\begin{array}{l}\frac{m}{0} \\
\frac{0}{0} \\
0\end{array}$ & $\begin{array}{l}\stackrel{1}{\infty} \\
\frac{0}{0}\end{array}$ & $\begin{array}{l}0 \\
\\
\\
\end{array}$ & $\begin{array}{l}\text { ฐ̃ } \\
\stackrel{-}{\circ}\end{array}$ & & $\begin{array}{l}\frac{g}{8} \\
\frac{R}{6} \\
0\end{array}$ \\
\hline & $\begin{array}{l}\bar{\Xi} \\
\frac{\bar{g}}{n} \\
\Leftrightarrow\end{array}$ & $\begin{array}{l}\text { סू } \\
\text { g్ } \\
0\end{array}$ & 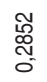 & \begin{tabular}{l}
\multirow{్}{0}{} \\
O \\
0
\end{tabular} & $\frac{\stackrel{\infty}{m}}{\frac{\infty}{0}}$ & 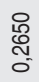 & 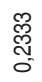 & $\begin{array}{l}\text { స̃ } \\
\text { O. } \\
0 \\
0\end{array}$ & 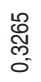 & 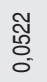 & $\begin{array}{l}\mathscr{O} \\
\text { o. } \\
0 \\
0\end{array}$ & 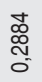 & 总 & $\begin{array}{l}\text { d } \\
\stackrel{\text { N }}{0} \\
0\end{array}$ & & $\begin{array}{l}\infty \\
\stackrel{0}{0} \\
0 \\
0\end{array}$ \\
\hline & $\theta$ & $\begin{array}{l}\frac{10}{\infty} \\
\frac{\infty}{0} \\
\end{array}$ & $\begin{array}{l}\bar{s} \\
\stackrel{5}{0}\end{array}$ & $\frac{\frac{m}{\infty}}{\frac{\infty}{0}}$ & $\frac{\bar{\infty}}{\overline{-}}$ & $\begin{array}{l}\frac{\infty}{8} \\
\frac{p}{0} \\
0\end{array}$ & $\begin{array}{l}\stackrel{8}{8} \\
\stackrel{8}{0} \\
0\end{array}$ & $\begin{array}{c}\text { o } \\
\frac{m}{-} \\
0\end{array}$ & $\begin{array}{l}\frac{0}{5} \\
\frac{1}{0}\end{array}$ & $\frac{\frac{5}{2}}{\frac{0}{0}}$ & $\begin{array}{l}\frac{\Re}{2} \\
\frac{1}{0} \\
\end{array}$ & $\begin{array}{l}\stackrel{8}{\infty} \\
\frac{0}{0}\end{array}$ & $\begin{array}{l}\infty \\
\stackrel{\infty}{0} \\
\frac{-}{0}\end{array}$ & $\begin{array}{l}\infty \\
\stackrel{0}{0} \\
0 \\
0\end{array}$ & & 尽 \\
\hline & U. & 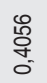 & $\underset{\substack{\hat{N} \\
\text { N }}}{ }$ & $\begin{array}{c}\stackrel{L}{0} \\
\text { } \\
0 \\
0\end{array}$ & $\frac{\stackrel{0}{0}}{\frac{0}{0}}$ & $\begin{array}{l}\text { 品 } \\
0 \\
0\end{array}$ & $\begin{array}{l}\underset{N}{N} \\
\text { J }\end{array}$ & $\begin{array}{l}\text { î̀ } \\
\text { i. } \\
\text { i. }\end{array}$ & 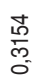 & $\begin{array}{l}\text { त్̃ } \\
\text { O. } \\
0\end{array}$ & $\begin{array}{c}\text { o } \\
\text { o. } \\
0 \\
0\end{array}$ & 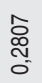 & 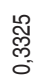 & م્ & & $\begin{array}{l}\frac{m}{0} \\
\stackrel{0}{0} \\
0\end{array}$ \\
\hline & $\vec{a}$ & \begin{tabular}{l}
$\stackrel{0}{N}$ \\
\multirow{N}{0}{} \\
0
\end{tabular} & 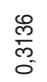 & 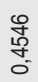 & 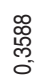 & 畩 & 点 & $\begin{array}{l}\text { هి } \\
\text { O. } \\
0\end{array}$ & 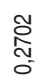 & 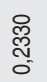 & స్心్ & $\begin{array}{l}\mathscr{8} \\
\substack{0 \\
0 \\
0}\end{array}$ & 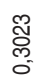 & $\begin{array}{l}\stackrel{P}{N} \\
\frac{1}{0}\end{array}$ & & 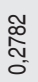 \\
\hline & $\stackrel{n}{\tilde{\tilde{z}}}$ & 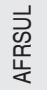 & 感 & $\stackrel{0}{\mathcal{Z}}$ & 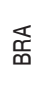 & સ્ડ & 퐁 & ठ઼ & 鿖 & 壱 & 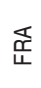 & 오 & $\Xi$ & $\frac{0}{5}$ & $\stackrel{\infty}{\vec{x}}$ & $\sum_{k}$ \\
\hline \multirow{8}{*}{ 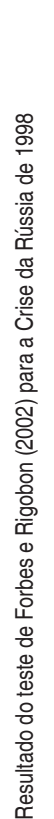 } & 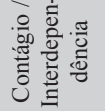 & - & - & - & - & - & - & - & - & - & - & - & - & - & & - \\
\hline & 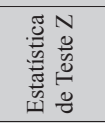 & 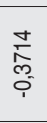 & 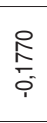 & 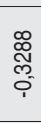 & 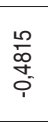 & $\begin{array}{l}\frac{1}{0} \\
\text { o } \\
\text { o. }\end{array}$ & $\begin{array}{l}\text { 足 } \\
\text { 皁 } \\
\text { - }\end{array}$ & $\begin{array}{l}\text { 产 } \\
\text { i. }\end{array}$ & $\begin{array}{l}0 \\
0 \\
0 \\
0\end{array}$ & 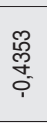 & $\begin{array}{l}\text { 苑 } \\
\text { o. }\end{array}$ & 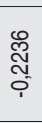 & $\begin{array}{l}\text { ô } \\
\text { : } \\
\text { i }\end{array}$ & $\begin{array}{l}\frac{0}{0} \\
\frac{0}{1}\end{array}$ & & $\begin{array}{l}\frac{0}{i} \\
\text { i } \\
\text { i }\end{array}$ \\
\hline & 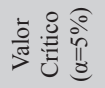 & ه্ & \&্০ & $\begin{array}{l}8 \\
\stackrel{8}{-} \\
-\end{array}$ & 兽 & $\begin{array}{l}8 \\
: \\
-\end{array}$ & $\begin{array}{l}\text { o } \\
\text { : } \\
-\end{array}$ & $\begin{array}{l}8 \\
\text { o } \\
-\end{array}$ & ه্ণ & 。্চ & $\begin{array}{l}8 \\
\text { ष्. } \\
-\end{array}$ & ه্ & 兽 & $\begin{array}{l}8 \\
\text { \& } \\
-\end{array}$ & & $\begin{array}{l}8 \\
\stackrel{8}{-}\end{array}$ \\
\hline & ○ & 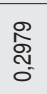 & $\begin{array}{l}\text { \% } \\
\stackrel{\circ}{\circ} \\
-\end{array}$ & 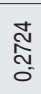 & $\begin{array}{l}\text { 范 } \\
\text { O. }\end{array}$ & 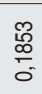 & $\begin{array}{l}\mathscr{0} \\
\frac{0}{0} \\
0\end{array}$ & $\begin{array}{l}\overline{0} \\
\text { o. } \\
0 \\
\end{array}$ & $\begin{array}{l}\mathcal{O} \\
\stackrel{\text { N }}{0} \\
\text { - }\end{array}$ & $\begin{array}{l}\text { क्ष } \\
\text { O. } \\
0\end{array}$ & $\begin{array}{l}\text { o } \\
\text { N. } \\
0 \\
0\end{array}$ & \begin{tabular}{l}
\multirow{2}{*}{} \\
D. \\
0
\end{tabular} & $\begin{array}{l}\text { O্ } \\
\text { d } \\
\text { o }\end{array}$ & $\begin{array}{l}\widehat{\infty} \\
\text { o } \\
0 \\
0\end{array}$ & & 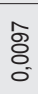 \\
\hline & Uू & 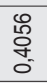 & $\underset{\substack{\hat{N} \\
\text { O } \\
0}}{ }$ & $\begin{array}{c}\mathscr{L} \\
\stackrel{0}{0} \\
0 \\
0 \\
0\end{array}$ & 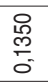 & $\begin{array}{l}\text { 囹 } \\
0\end{array}$ & 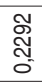 & 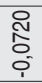 & 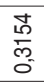 & 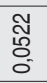 & $\begin{array}{c}8 \\
\text { o } \\
0 \\
0 \\
0\end{array}$ & 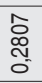 & $\begin{array}{l}\text { ్ָల్ } \\
\text { ర్ } \\
0\end{array}$ & $\begin{array}{l}\text { స్ } \\
\text { 엉 }\end{array}$ & & $\begin{array}{l}\infty \\
0 \\
0 \\
0 \\
0\end{array}$ \\
\hline & 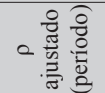 & $\begin{array}{l}\mathbb{J} \\
\mathbb{0} \\
0 \\
0\end{array}$ & 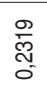 & 莶 & $\frac{\text { I }}{\frac{\infty}{0}}$ & $\begin{array}{l}\text { ồ } \\
\text { v } \\
\text { d. }\end{array}$ & $\stackrel{f}{q}$ & 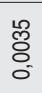 & 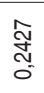 & $\underset{⿱ 乛}{\stackrel{\Gamma}{0}}$ & 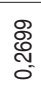 & 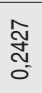 & 菍 & $\begin{array}{l}\mathscr{2} \\
\stackrel{0}{0} \\
0\end{array}$ & & $\frac{\stackrel{\mathscr{L}}{\sigma}}{\stackrel{\circ}{\circ}}$ \\
\hline & 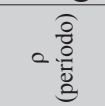 & 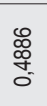 & 을 & 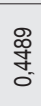 & 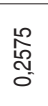 & $\begin{array}{l}\text { 怘 } \\
\stackrel{m}{0} \\
0\end{array}$ & 章 & $\begin{array}{l}\text { 영 } \\
0 \\
0\end{array}$ & 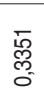 & $\begin{array}{l}\frac{\pi}{0} \\
\frac{0}{0} \\
0\end{array}$ & $\begin{array}{l}\text { o } \\
\text { m. } \\
0\end{array}$ & 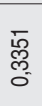 & 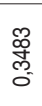 & 兽 & & $\begin{array}{l}\infty \\
\text { o } \\
\text { N } \\
0\end{array}$ \\
\hline & $\stackrel{\mathscr{\mu}}{\tilde{\Perp}}$ & 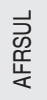 & 焉 & $\stackrel{0}{\&}$ & 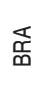 & કે & $\overline{\mathrm{I}}$ & ठ․ & 嵒 & 胥 & $\underset{\mathbb{4}}{\mathbb{\leftrightarrow}}$ & 오 & $\Xi$ & $\frac{0}{5}$ & $\stackrel{\infty}{\vec{x}}$ & $\sum_{k}$ \\
\hline
\end{tabular}




\begin{tabular}{|c|c|c|c|c|c|c|c|c|c|c|c|c|c|c|c|c|}
\hline \multirow{10}{*}{ 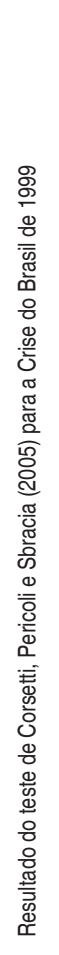 } & 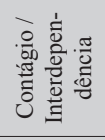 & - & 0 & - & & 0 & 0 & - & - & 0 & - & - & - & - & - & - \\
\hline & 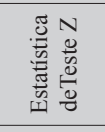 & 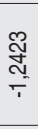 & 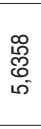 & 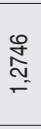 & & 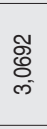 & 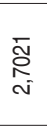 & $\frac{\frac{0}{0}}{\frac{1}{6}}$ & $\begin{array}{l}\overline{0} \\
\stackrel{-}{0} \\
\overline{1}\end{array}$ & $\frac{\frac{m}{\sigma}}{m^{-}}$ & $\begin{array}{l}\infty \\
0_{0}^{\circ} \\
0 . \\
0 .\end{array}$ & 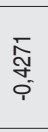 & 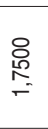 & 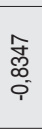 & $\begin{array}{l}\mathscr{0} \\
\stackrel{8}{8} \\
0 \\
0 \\
\end{array}$ & 总 \\
\hline & 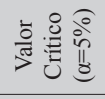 & $\begin{array}{l}8 \\
8 \\
- \\
-\end{array}$ & ه্চ & ষ্ণ & & $\begin{array}{l}8 \\
8 \\
- \\
-\end{array}$ & $\begin{array}{l}\stackrel{8}{\circ} \\
\stackrel{-}{-}\end{array}$ & $\begin{array}{l}\stackrel{8}{\circ} \\
\stackrel{-}{-}\end{array}$ & $\begin{array}{l}\stackrel{8}{\circ} \\
\stackrel{-}{-}\end{array}$ & $\begin{array}{l}8 \\
\stackrel{\circ}{\circ} \\
-\end{array}$ & $\begin{array}{l}\stackrel{8}{\circ} \\
\stackrel{\circ}{-}\end{array}$ & $\begin{array}{l}8 \\
\stackrel{\circ}{\circ} \\
-\end{array}$ & $\begin{array}{l}8 \\
\stackrel{\circ}{\circ} \\
-\end{array}$ & ه্ & \&. & $\begin{array}{l}8 \\
\stackrel{\circ}{\circ}\end{array}$ \\
\hline & $\tilde{\sigma}$ & $\begin{array}{l}\mathscr{0} \\
\frac{\infty}{-} \\
0\end{array}$ & $\begin{array}{l}\mathscr{0} \\
\infty \\
0 \\
0\end{array}$ & $\underset{\circledast}{\dddot{\Xi}}$ & & $\begin{array}{l}\dddot{10} \\
\frac{0}{0} \\
0\end{array}$ & $\begin{array}{l}\mathbb{0} \\
\frac{\infty}{0} \\
0\end{array}$ & $\begin{array}{l}\mathbb{0} \\
\frac{\infty}{0} \\
0\end{array}$ & $\begin{array}{l}\frac{\pi}{0} \\
\frac{0}{0} \\
0\end{array}$ & $\begin{array}{l}\dddot{\infty} \\
\frac{\infty}{-0} \\
0\end{array}$ & $\begin{array}{l}\dddot{\infty} \\
\infty \\
0 \\
0\end{array}$ & $\begin{array}{l}\dddot{\infty} \\
\infty \\
0 \\
0\end{array}$ & $\begin{array}{l}\frac{\pi}{\infty} \\
\frac{\infty}{0} \\
0\end{array}$ & $\begin{array}{l}\frac{\pi}{\infty} \\
\frac{\infty}{0}\end{array}$ & $\begin{array}{l}0 \\
0 \\
0 \\
0\end{array}$ & $\begin{array}{l}\mathscr{0} \\
\stackrel{0}{0} \\
0\end{array}$ \\
\hline & 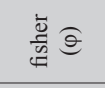 & $\begin{array}{l}\text { 유 } \\
\text { స్ } \\
\text { - }\end{array}$ & 응 & $\begin{array}{l}\frac{\bar{\alpha}}{\sigma} \\
\overline{0}\end{array}$ & & $\begin{array}{l}8 \\
8 \\
0\end{array}$ & $\begin{array}{l}8 \\
8 \\
0\end{array}$ & 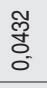 & $\begin{array}{l}\overline{8} \\
\vdots \\
0\end{array}$ & $\begin{array}{l}8 \\
8 \\
0\end{array}$ & 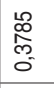 & $\frac{\widetilde{N}}{\frac{\tilde{g}}{\sigma}}$ & $\frac{\widetilde{m}}{\circ}$ & $\frac{\stackrel{ \pm}{ \pm}}{\underset{0}{0}}$ & $\begin{array}{l}\frac{8}{0} \\
\frac{1}{6}\end{array}$ & 足 \\
\hline & 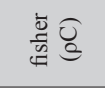 & 盽 & $\begin{array}{l}\text { 웅 } \\
\text { 음 }\end{array}$ & 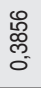 & & 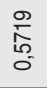 & $\begin{array}{l}\text { 员 } \\
0 \\
0 \\
0\end{array}$ & $\begin{array}{l}\frac{9}{9} \\
0 \\
0 \\
0\end{array}$ & $\begin{array}{l}\infty \\
: \\
\vdots \\
0 \\
0\end{array}$ & 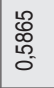 & 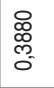 & $\begin{array}{l}\hat{0} \\
\tilde{0} \\
0\end{array}$ & $\begin{array}{l}\text { 总 } \\
\text { 㕝 } \\
0\end{array}$ & 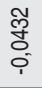 & 훙 & $\begin{array}{l}\text { 昌 } \\
\text { 定 }\end{array}$ \\
\hline & $\theta$ & 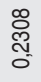 & ০০ & $\frac{8}{\frac{8}{5}}$ & & $\begin{array}{l}8 \\
8 \\
0\end{array}$ & $\begin{array}{l}8 \\
: \\
0\end{array}$ & $\begin{array}{l}\widetilde{\tilde{g}} \\
\stackrel{0}{0}\end{array}$ & $\begin{array}{l}\mathbb{Z} \\
\substack{0 \\
0 \\
0}\end{array}$ & $\begin{array}{l}\text { ¿ } \\
\text { : }\end{array}$ & $\begin{array}{l}\vec{J} \\
\overline{0} \\
0 \\
0\end{array}$ & $\frac{\stackrel{\mathscr{J}}{\Im}}{0}$ & 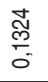 & $\frac{0}{\stackrel{2}{2}}$ & $\frac{\mathcal{N}}{\frac{N}{0}}$ & $\begin{array}{l}\infty \\
\stackrel{\infty}{0} \\
0 \\
0\end{array}$ \\
\hline & U. & 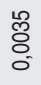 & $\begin{array}{l}\frac{0}{0} \\
\stackrel{0}{0} \\
0\end{array}$ & $\begin{array}{l}0 \\
0 \\
0 \\
0\end{array}$ & & $\begin{array}{l}\infty \\
\frac{0}{0} \\
0 \\
0\end{array}$ & 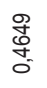 & $\begin{array}{l}\stackrel{9}{0} \\
\stackrel{0}{0} \\
0\end{array}$ & 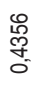 & 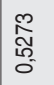 & $\begin{array}{l}0 \\
8 \\
o \\
0 \\
0\end{array}$ & $\begin{array}{l}\mathscr{0} \\
\ddot{0} \\
0\end{array}$ & $\begin{array}{l}\text { 怘 } \\
\text { đ̆ } \\
0\end{array}$ & $\begin{array}{l}\bar{s} \\
\text { ơ } \\
\text { i. }\end{array}$ & 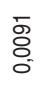 & 亭 \\
\hline & $\bar{a}$ & $\begin{array}{l}\text { o. } \\
\text { o } \\
\text { o }\end{array}$ & $\begin{array}{l}\stackrel{8}{8} \\
\stackrel{8}{\circ} \\
0\end{array}$ & $\begin{array}{l}\stackrel{\Xi}{0} \\
\text { N̦ } \\
0\end{array}$ & & $\begin{array}{l}\hat{\widetilde{O}} \\
\text { ণ্} \\
\text { - }\end{array}$ & $\begin{array}{l}\stackrel{0}{\circ} \\
0 \\
0\end{array}$ & $\begin{array}{l}\mathscr{0} \\
\stackrel{0}{0} \\
0 \\
0\end{array}$ & 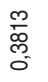 & $\begin{array}{l}\overline{0} \\
\stackrel{0}{0} \\
0\end{array}$ & 兽 & $\begin{array}{l}\text { 을 } \\
\text { స్ } \\
0\end{array}$ & 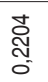 & $\frac{\infty}{\sigma}$ & 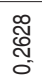 & 总 \\
\hline & 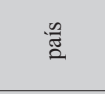 & 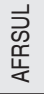 & $\begin{array}{l}\text { 足 } \\
\text { }\end{array}$ & $\stackrel{\text { DO }}{\mathcal{2}}$ & $\underset{\substack{\mathbf{c} \\
\mathbf{c}}}{ }$ & 忢 & 퐁 & ठ․ & 苫 & 豈 & 氐 & 오 & 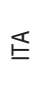 & $\frac{0}{5}$ & $\stackrel{\mathscr{N}}{\underset{\sim}{2}}$ & $\sum_{k}$ \\
\hline \multirow{8}{*}{ 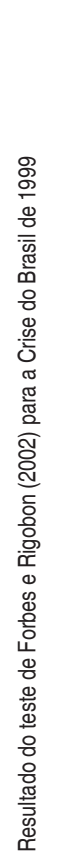 } & 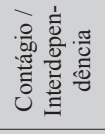 & - & - & - & & - & - & - & - & - & - & - & - & - & - & - \\
\hline & 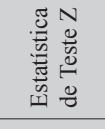 & \begin{tabular}{c}
$\stackrel{2}{N}$ \\
\multirow{i}{*}{} \\
$i$
\end{tabular} & $\frac{0}{\frac{0}{0}}$ & 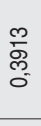 & & $\begin{array}{l}\stackrel{\mathscr{0}}{\infty} \\
\frac{\infty}{0}\end{array}$ & 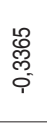 & 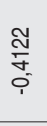 & $\begin{array}{l}\text { 芯 } \\
\text { đ. }\end{array}$ & 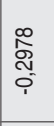 & $\frac{0}{\frac{1}{2}}$ & 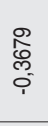 & $\begin{array}{l}\text { 太ิ } \\
0 \\
0\end{array}$ & 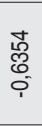 & 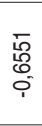 & $\begin{array}{l}\text { ్ָ } \\
\text { ర్ } \\
0\end{array}$ \\
\hline & 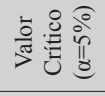 & $\begin{array}{l}8 \\
8 \\
:\end{array}$ & 怘 & $\begin{array}{l}\stackrel{8}{\circ} \\
\stackrel{8}{-}\end{array}$ & & \begin{tabular}{l}
8 \\
8 \\
\hdashline \\
-
\end{tabular} & 怘 & $\begin{array}{l}\stackrel{8}{\circ} \\
\stackrel{-}{-}\end{array}$ & 品 & $\begin{array}{l}8 \\
\stackrel{\circ}{\circ} \\
-\end{array}$ & $\begin{array}{l}\stackrel{8}{\circ} \\
\stackrel{\circ}{-}\end{array}$ & ه্ঠ & ষ্ণ & ه্ঠ & \&: & $\stackrel{8}{8}$ \\
\hline & 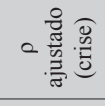 & 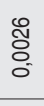 & $\begin{array}{l}\text { Õ } \\
\text { o. } \\
0\end{array}$ & $\begin{array}{l}\mathscr{D} \\
\stackrel{\infty}{0} \\
0 \\
0\end{array}$ & & 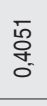 & 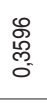 & $\begin{array}{l}8 \\
\text { 음 } \\
0\end{array}$ & $\begin{array}{l}\text { fy } \\
\text { m } \\
0\end{array}$ & $\frac{\substack{0 \\
\sigma \\
0}}{0}$ & 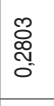 & $\begin{array}{l}\hat{o} \\
0 \\
0 \\
0\end{array}$ & $\begin{array}{l}\mathscr{\%} \\
\text { ल. } \\
0\end{array}$ & 商 & 周 & $\begin{array}{l}\frac{\infty}{0} \\
\frac{5}{0}\end{array}$ \\
\hline & $\bigcup_{a}$ & $\begin{array}{l}\text { ஜू } \\
\text { o. } \\
0\end{array}$ & $\begin{array}{l}\frac{0}{0} \\
\frac{0}{0} \\
0 \\
0\end{array}$ & $\begin{array}{l}0 \\
0 \\
0 \\
0 \\
0\end{array}$ & & $\begin{array}{l}0 \\
\frac{0}{0} \\
i 0 \\
0\end{array}$ & $\begin{array}{l}\frac{9}{1} \\
0 \\
0 \\
0 \\
0\end{array}$ & $\frac{g}{\frac{g}{0}}$ & 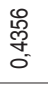 & 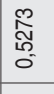 & $\begin{array}{l}\mathscr{8} \\
0 \\
0 \\
0\end{array}$ & $\begin{array}{l}\text { \% } \\
\varnothing 0 \\
0\end{array}$ & $\begin{array}{l}\stackrel{\leftrightarrow}{\sim} \\
\text { c. } \\
0\end{array}$ & $\begin{array}{l}\bar{s} \\
\text { ơ } \\
\text { i. }\end{array}$ & 형 & 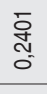 \\
\hline & 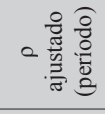 & $\frac{9}{\frac{9}{0}}$ & $\begin{array}{l}\text { 呆 } \\
\text { O } \\
0\end{array}$ & Nิ & & 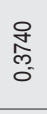 & $\begin{array}{l}\frac{8}{6} \\
\frac{6}{6} \\
0\end{array}$ & $\begin{array}{l}\bar{\tau} \\
0 \\
0 \\
0\end{array}$ & 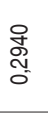 & 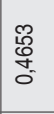 & 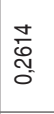 & $\frac{8}{\circ}$ & $\begin{array}{l}\text { ָ̃ } \\
\text { స్ } \\
0\end{array}$ & $\begin{array}{l}\qquad 0 \\
0 \\
0 \\
0\end{array}$ & 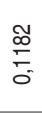 & $\frac{?}{\frac{P}{0}}$ \\
\hline & $=\frac{\frac{\sigma}{0}}{0}$ & $\frac{\pi}{0}$ & $\begin{array}{l}\text { ஜ్ర } \\
\text { o }\end{array}$ & $\begin{array}{l}\mathscr{心} \\
\text { 心్ } \\
0\end{array}$ & & 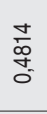 & $\begin{array}{l}\stackrel{8}{\mathrm{~N}} \\
\text { 엉 }\end{array}$ & $\frac{\overline{0}}{c}$ & $\begin{array}{l}\mathbb{Z} \\
\text { o } \\
\text { o. } \\
0\end{array}$ & 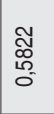 & $\begin{array}{l}\overline{6} \\
\text { 产 } \\
0\end{array}$ & $\frac{\widetilde{O}}{\stackrel{\alpha}{\sigma}}$ & $\begin{array}{l}\text { N. } \\
\text { 心 } \\
\text { o. }\end{array}$ & $\frac{0}{0}$ & \begin{tabular}{l}
$\bar{\sigma}$ \\
\hdashline \\
0
\end{tabular} & $\begin{array}{l}\stackrel{2}{\circ} \\
\stackrel{\circ}{\circ} \\
0\end{array}$ \\
\hline & : & $\begin{array}{l}\bar{y} \\
\end{array}$ & 立 & 宸 & 总 & 孞 & 复 & ठ઼ & $\begin{array}{l}\text { 岀 } \\
\text { }\end{array}$ & 吉 & 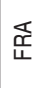 & 오 & 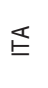 & $\frac{0}{5}$ & $\stackrel{\mathscr{D}}{\underset{\alpha}{2}}$ & $\sum_{k}$ \\
\hline
\end{tabular}




\begin{tabular}{|c|c|c|c|c|c|c|c|c|c|c|c|c|c|c|c|c|}
\hline \multirow{10}{*}{ 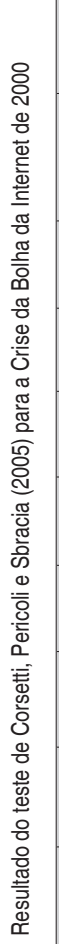 } & 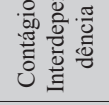 & 0 & 0 & - & - & 0 & - & - & - & & - & - & - & - & - & - \\
\hline & 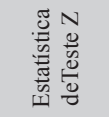 & ్ָల్లై & $\begin{array}{l}0 \\
0 \\
0 \\
0 \\
-\infty\end{array}$ & 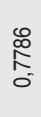 & 兽 & $\frac{\pi}{\infty}$ & 惫 & $\begin{array}{l}\text { o } \\
\text { o } \\
\text { 웅 }\end{array}$ & $\begin{array}{l}\text { 웅 } \\
\text { o. } \\
0\end{array}$ & & $\begin{array}{l}\mathscr{8} \\
\mathbb{0} \\
0 \\
0\end{array}$ & 命 & $\begin{array}{l}\text { O్ } \\
0 \\
0 \\
0\end{array}$ & $\begin{array}{l}\frac{8}{8} \\
\vdots \\
0\end{array}$ & $\begin{array}{l}\text { 吉 } \\
\text { o. } \\
\text { o. }\end{array}$ & 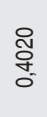 \\
\hline & 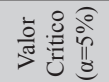 & 吕 & 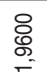 & $\begin{array}{l}8 \\
\stackrel{8}{-} \\
-\end{array}$ & 各 & : & $\begin{array}{l}8 \\
\stackrel{8}{\circ} \\
-\end{array}$ & $\begin{array}{l}\stackrel{8}{\circ} \\
\stackrel{-}{\leftarrow}\end{array}$ & \begin{tabular}{l}
8 \\
8 \\
\hdashline \\
-
\end{tabular} & & $\stackrel{8}{\circ}$ & $\begin{array}{l}\stackrel{8}{\circ} \\
\stackrel{-}{-}\end{array}$ & \& & \& & $\begin{array}{l}8 \\
\stackrel{\circ}{\circ} \\
\stackrel{-}{-}\end{array}$ & $\begin{array}{l}\stackrel{8}{\circ} \\
\stackrel{-}{-}\end{array}$ \\
\hline & $\tilde{\sigma}$ & $\begin{array}{l}\text { o̊ } \\
\text { o. } \\
0\end{array}$ & $\begin{array}{l}\text { o̊ } \\
\text { o. } \\
0\end{array}$ & $\begin{array}{l}\text { Iิ } \\
\text { o. } \\
0\end{array}$ & 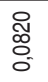 & $\begin{array}{l}\text { oิ } \\
\text { ơ } \\
0\end{array}$ & $\begin{array}{l}\text { ఖ్ } \\
\text { o. } \\
0\end{array}$ & $\begin{array}{l}\text { ळ్ } \\
\text { o. } \\
0\end{array}$ & $\begin{array}{l}\text { Iิ } \\
\text { o. } \\
\text { - }\end{array}$ & & $\begin{array}{l}\text { o్ } \\
\text { o. }\end{array}$ & 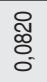 & $\begin{array}{l}\text { ळ్ } \\
\text { : } \\
\text { - }\end{array}$ & 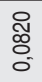 & 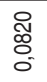 & $\begin{array}{l}\text { \&్ } \\
\text { : } \\
\text { ○. }\end{array}$ \\
\hline & 离 & $\frac{8}{\frac{8}{0}}$ & $\begin{array}{l}8 \\
\stackrel{0}{0} \\
0 \\
0\end{array}$ & $\begin{array}{l}\hat{\infty} \\
0 \\
0 \\
0\end{array}$ & $\begin{array}{l}\text { 苍 } \\
\text { on } \\
0\end{array}$ & $\begin{array}{l}\text { 呆 } \\
\text { 足 } \\
0\end{array}$ & 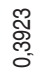 & 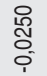 & 疍 & & $\begin{array}{l}0 \\
\text { fo } \\
0 \\
0\end{array}$ & 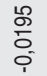 & $\begin{array}{c}\overline{\mathscr{J}} \\
\text { O. } \\
\text { - }\end{array}$ & 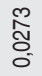 & $\begin{array}{l}\infty \\
\text { o } \\
0 \\
0\end{array}$ & $\begin{array}{l}\text { To } \\
0 \\
0\end{array}$ \\
\hline & 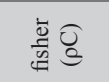 & 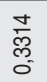 & $\begin{array}{l}\text { o. } \\
\text { đ్ } \\
0\end{array}$ & \begin{tabular}{l}
$\mathscr{8}$ \\
\multirow{2}{*}{} \\
0
\end{tabular} & 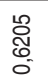 & $\begin{array}{l}\frac{\infty}{0} \\
\frac{0}{\sigma} \\
0\end{array}$ & $\begin{array}{l}\text { స్̃ } \\
\text { bू } \\
0\end{array}$ & 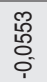 & $\begin{array}{l}\stackrel{9}{9} \\
\text { go } \\
0\end{array}$ & & $\begin{array}{l}\mathscr{O} \\
\stackrel{P}{+} \\
0\end{array}$ & $\begin{array}{l}\stackrel{2}{0} \\
0 \\
0 \\
0\end{array}$ & $\begin{array}{l}\text { స్త } \\
\text { ơ } \\
\text { o }\end{array}$ & $\frac{10}{8}$ & 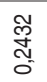 & $\begin{array}{l}\overline{0} \\
0 \\
0 \\
0\end{array}$ \\
\hline & $\theta$ & $\frac{\bar{m}}{\overline{0}}$ & $\begin{array}{l}\text { o } \\
\text { 足 } \\
\text { O. }\end{array}$ & $\begin{array}{l}0 \\
\mathbb{0} \\
0 \\
0\end{array}$ & $\begin{array}{l}\text { đo } \\
\vdots \\
0 \\
0\end{array}$ & $\begin{array}{c}\frac{9}{4} \\
\text { fo } \\
0\end{array}$ & 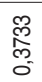 & 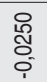 & $\begin{array}{l}\text { 总 } \\
\text { o. } \\
0\end{array}$ & & 兽 & $\begin{array}{l}\text { ळ } \\
\vdots \\
\vdots \\
\end{array}$ & $\begin{array}{l}\text { N } \\
\text { ल. } \\
\text { o. } \\
0\end{array}$ & 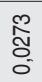 & $\begin{array}{l}\approx \\
\vdots \\
0 \\
0\end{array}$ & $\begin{array}{l}\overline{0} \\
\text { O. } \\
0\end{array}$ \\
\hline & U. & $\frac{\infty}{0}$ & $\begin{array}{l}\hat{0} \\
\text { 员 } \\
0\end{array}$ & 迤 & 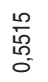 & $\begin{array}{l}\text { N్ } \\
\text { N. }\end{array}$ & \begin{tabular}{l} 
f \\
\multirow{d}{*}{} \\
0
\end{tabular} & $\begin{array}{l}\text { 员 } \\
\text { o. } \\
\text { ○. }\end{array}$ & 疋 & & 章 & $\begin{array}{l}\text { वे } \\
0 \\
0 \\
0\end{array}$ & 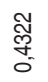 & $\frac{\pi}{8}$ & 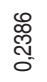 & $\begin{array}{l}8 \\
\vdots \\
0 \\
0\end{array}$ \\
\hline & $\bar{a}$ & $\underset{0}{\stackrel{N}{0}}$ & $\begin{array}{c}\infty \\
\frac{\infty}{0} \\
0 \\
0\end{array}$ & o్ల్య & $\begin{array}{l}\stackrel{2}{0} \\
\stackrel{W}{G} \\
0\end{array}$ & $\begin{array}{l}\overline{0} \\
0 \\
0 \\
0\end{array}$ & 亮 & 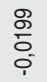 & $\frac{⿱}{0}$ & & $\begin{array}{l}\text { 兽 } \\
0 \\
0\end{array}$ & $\begin{array}{l}\stackrel{0}{\circ} \\
\stackrel{\circ}{0} \\
0 \\
\\
\end{array}$ & $\begin{array}{l}\text { o్ } \\
\text { ల్ల } \\
0\end{array}$ & సे. & $\begin{array}{l}\hat{0} \\
\frac{m}{0}\end{array}$ & 怘 \\
\hline & 总 & 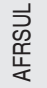 & 焉 & $\stackrel{n}{2}$ & 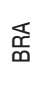 & 否 & 퐁 & $\overrightarrow{0}$ & 号 & 豈 & 氶 & 오 & $\Xi$ & 足 & $\stackrel{\mathscr{D}}{\vec{x}}$ & $\sum_{k}$ \\
\hline ষ্ণ & 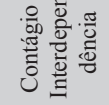 & - & - & - & - & - & - & - & - & & - & - & - & - & - & - \\
\hline 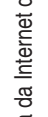 & 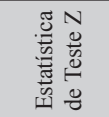 & 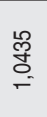 & 总 & $\begin{array}{l}\text { o } \\
\text { o } \\
\text { 足 }\end{array}$ & $\begin{array}{l}\text { वे } \\
\varnothing \\
0 \\
0\end{array}$ & $\begin{array}{l}\text { o } \\
\text { ơ } \\
\text { o }\end{array}$ & $\frac{E}{6}$ & $\frac{\mathbb{N}}{\stackrel{N}{\circ}}$ & $\begin{array}{l}\text { o } \\
\text { ơ } \\
\text { o }\end{array}$ & & 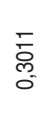 & 姺 & $\begin{array}{l}\text { 员 } \\
\text { 员 } \\
0\end{array}$ & 总 & $\begin{array}{l}\text { Dิ } \\
0 \\
0 \\
0\end{array}$ & 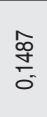 \\
\hline 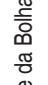 & 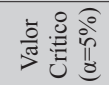 & $\stackrel{8}{\circ}$ & $\begin{array}{l}\stackrel{8}{\circ} \\
\stackrel{-}{-}\end{array}$ & $\begin{array}{l}8 \\
8 \\
-\end{array}$ & 足 & $\begin{array}{l}8 \\
\stackrel{8}{-}\end{array}$ & 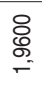 & $\stackrel{8}{\circ}$ & $\begin{array}{l}\stackrel{8}{\circ} \\
\stackrel{\circ}{-}\end{array}$ & & 윰 & $\stackrel{8}{\circ}$ & ه্ঠ & \&: & 。: & $\stackrel{8}{\circ}$ \\
\hline 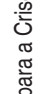 & 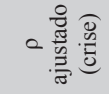 & $\begin{array}{l}\bar{\Xi} \\
\stackrel{0}{0} \\
0\end{array}$ & $\begin{array}{l}\stackrel{8}{0} \\
\text { co } \\
0 \\
0\end{array}$ & $\begin{array}{l}\text { ఫ్ } \\
\text { o. } \\
0\end{array}$ & $\begin{array}{l}\stackrel{0}{\circ} \\
\stackrel{2}{+} \\
0\end{array}$ & 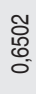 & $\begin{array}{l}\text { \% } \\
\text { d } \\
0 \\
0\end{array}$ & $\begin{array}{l}\text { ত̃ } \\
0 \\
0 \\
0\end{array}$ & 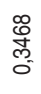 & & $\begin{array}{l}\underset{K}{K} \\
\text { O. } \\
0\end{array}$ & \begin{tabular}{l}
0 \\
\multirow{2}{0}{} \\
0
\end{tabular} & $\begin{array}{l}\text { 잉 } \\
\text { o } \\
0\end{array}$ & $\begin{array}{l}\text { 号 } \\
\text { o. } \\
0\end{array}$ & $\frac{?}{0}$ & 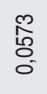 \\
\hline 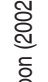 & Uू & 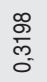 & $\begin{array}{l}\hat{0} \\
\text { 㟔 } \\
0 \\
0\end{array}$ & 粫 & 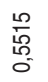 & 胥 & $\begin{array}{l}\text { 学 } \\
\text { ơ } \\
0\end{array}$ & $\begin{array}{l}\text { 茴 } \\
\text { ○. }\end{array}$ & 总 & & 竎 & \begin{tabular}{l}
\multirow{2}{0}{} \\
: \\
0
\end{tabular} & 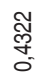 & $\frac{\nabla}{8}$ & 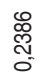 & $\begin{array}{l}\text { ㅇ. } \\
\text { : } \\
\text { - }\end{array}$ \\
\hline 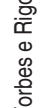 & 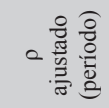 & $\frac{N}{0}$ & $\begin{array}{l}\text { 总 } \\
\text { c. } \\
0\end{array}$ & $\frac{0}{\overline{0}}$ & $\frac{\mathscr{m}}{\frac{\mathscr{m}}{\sigma}}$ & $\frac{\circ}{\frac{10}{0}}$ & $\begin{array}{l}\text { o. } \\
\text { m } \\
0\end{array}$ & 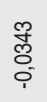 & 울 & & $\begin{array}{l}\text { 吕 } \\
\text { O } \\
0\end{array}$ & 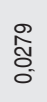 & $\begin{array}{l}\text { ్ָల్ల } \\
0\end{array}$ & $\begin{array}{l}\mathscr{8} \\
\text { O্. } \\
\text { O. }\end{array}$ & $\frac{\frac{0}{6}}{\frac{10}{0}}$ & $\begin{array}{l}\stackrel{8}{0} \\
\vdots \\
0\end{array}$ \\
\hline $\begin{array}{l}\frac{1}{0} \\
0 \\
\frac{0}{0} \\
\frac{0}{0} \\
0\end{array}$ & a. & 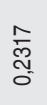 & 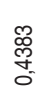 & 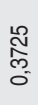 & 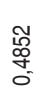 & $\begin{array}{l}\overline{8} \\
\stackrel{0}{\circ}\end{array}$ & 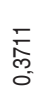 & 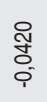 & $\begin{array}{l}\stackrel{L}{0} \\
\stackrel{0}{0} \\
0\end{array}$ & & $\underset{\hat{J}}{\hat{y}}$ & $\begin{array}{l}\bar{\delta} \\
\text { o. } \\
\text { o }\end{array}$ & $\begin{array}{l}\text { ఖ్ర } \\
\text { ల్ } \\
0\end{array}$ & 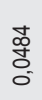 & $\begin{array}{l}\text { f } \\
\frac{\infty}{0} \\
0\end{array}$ & $\begin{array}{l}\text { R } \\
\text { o. } \\
0\end{array}$ \\
\hline 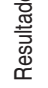 & 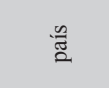 & 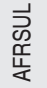 & 焉 & $\stackrel{2}{2}$ & 离 & ডิ & 퐁 & ठㅇ & 黛 & 孚 & 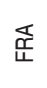 & 오 & 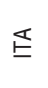 & 足 & $\stackrel{\mathscr{D}}{\sim}$ & $\sum_{k}$ \\
\hline
\end{tabular}




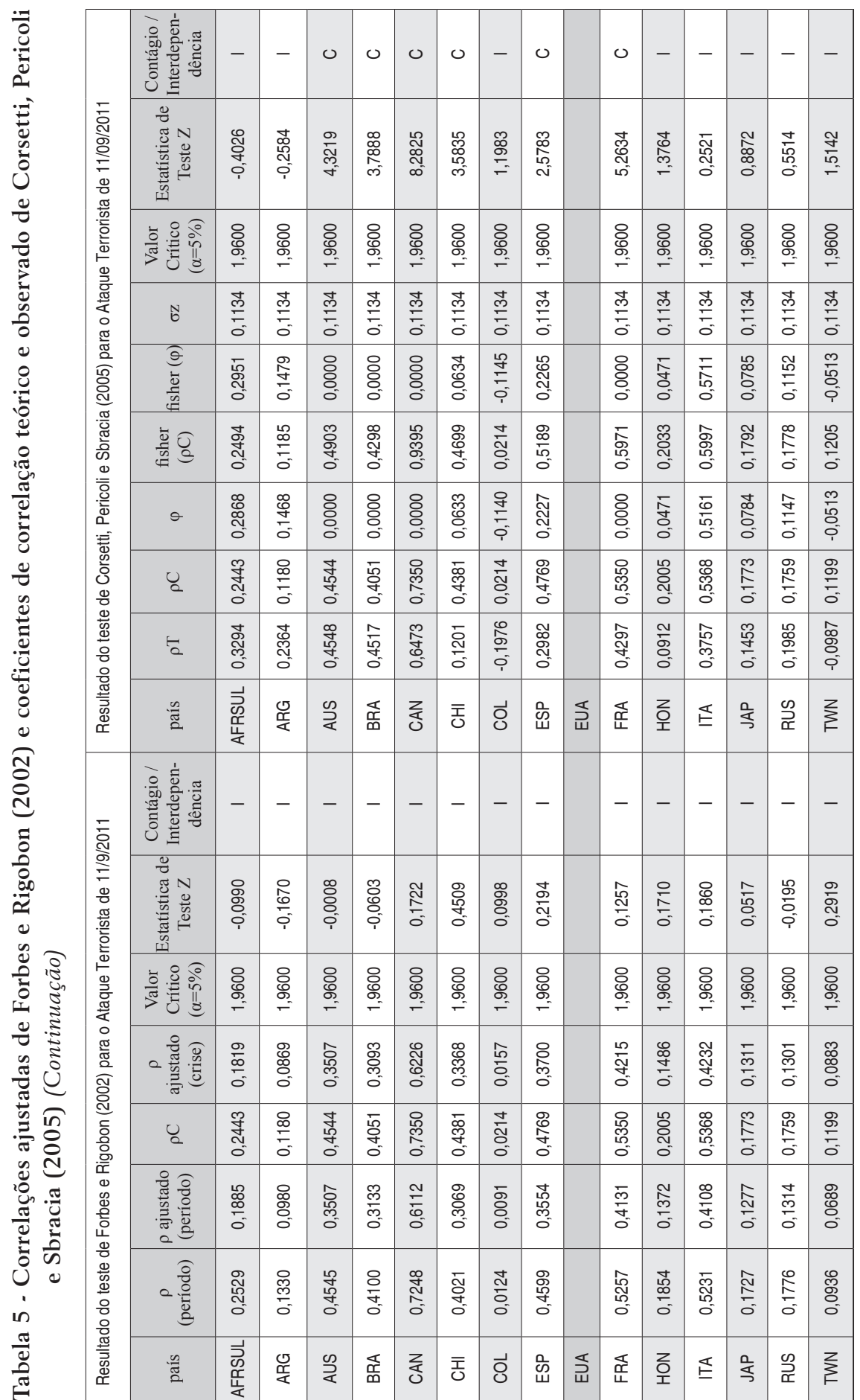




\begin{tabular}{|c|c|c|c|c|c|c|c|c|c|c|c|c|c|c|c|c|}
\hline \multirow{10}{*}{ 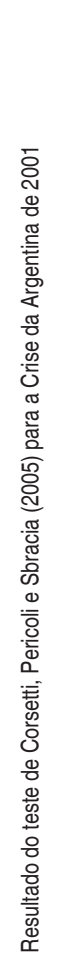 } & 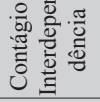 & - & & - & - & - & - & - & - & - & - & - & - & - & - & - \\
\hline & 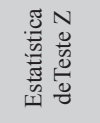 & $\stackrel{8}{\circ}$ & & 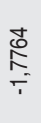 & 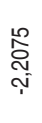 & 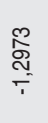 & 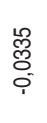 & 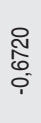 & 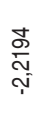 & 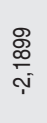 & 获 & \begin{tabular}{l}
$\mathscr{乛}$ \\
$\mathbb{8}$ \\
0 \\
\hdashline
\end{tabular} & 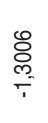 & $\frac{\infty}{\stackrel{m}{\frac{m}{-}}}$ & 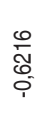 & $\begin{array}{l}\stackrel{8}{\circ} \\
\stackrel{0}{\circ} \\
0\end{array}$ \\
\hline & 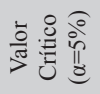 & 。্চ & & $\begin{array}{l}8 \\
\stackrel{\circ}{\circ} \\
\end{array}$ & $\begin{array}{l}8 \\
8 \\
:\end{array}$ & $\begin{array}{l}8 \\
8 \\
\stackrel{-}{-}\end{array}$ & 용- & $\begin{array}{l}8 \\
\text { o } \\
-\end{array}$ & $\begin{array}{l}\stackrel{8}{\circ} \\
\stackrel{-}{=}\end{array}$ & $\begin{array}{l}8 \\
\stackrel{\circ}{\circ} \\
-\end{array}$ & $\begin{array}{l}\text { o } \\
\stackrel{\circ}{-} \\
-\end{array}$ & 兽 & 兽 & ষ্ণ & 兽 & $\begin{array}{l}\stackrel{8}{\circ} \\
\stackrel{-}{\circ}\end{array}$ \\
\hline & ถิ & $\frac{8}{0}$ & & $\begin{array}{l}8 \\
\frac{8}{0} \\
0\end{array}$ & $\frac{8}{0}$ & $\frac{8}{\circ}$ & 용 & $\frac{8}{8}$ & $\frac{8}{\circ}$ & $\begin{array}{l}\frac{8}{0} \\
0\end{array}$ & 음 & $\begin{array}{l}\frac{8}{0} \\
\frac{0}{0}\end{array}$ & $\begin{array}{l}\text { 영 } \\
\text { 응 }\end{array}$ & $\frac{8}{\circ}$ & $\begin{array}{l}8 \\
\frac{8}{0} \\
\end{array}$ & $\begin{array}{l}8 \\
\frac{8}{0} \\
0\end{array}$ \\
\hline & $\frac{\bar{s}}{\tilde{n}} \widehat{\vartheta}$ & $\begin{array}{l}\stackrel{8}{0} \\
\frac{0}{0}\end{array}$ & & $\begin{array}{l}\hat{0} \\
\text { à } \\
\text { o. }\end{array}$ & 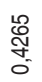 & 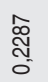 & $\begin{array}{l}\overline{0} \\
0 \\
0 \\
\end{array}$ & $\begin{array}{l}\infty \\
\infty \\
0 \\
\\
\end{array}$ & $\frac{8}{0}$ & 怘 & స్心 & 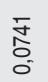 & 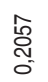 & 裵 & $\begin{array}{l}\text { वे } \\
\frac{0}{0}\end{array}$ & $\begin{array}{l}: \\
: \\
0 \\
0\end{array}$ \\
\hline & 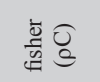 & 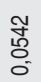 & & $\begin{array}{l}\text { त्र } \\
\text { O. } \\
0\end{array}$ & $\begin{array}{l}0 \\
\cong \\
0\end{array}$ & \begin{tabular}{l}
\multirow{0}{*}{} \\
$\stackrel{0}{0}$ \\
$0 .-0$
\end{tabular} & $\begin{array}{l}\frac{1}{0} \\
0 \\
0\end{array}$ & $\begin{array}{l}\hat{0} \\
\text { के } \\
\text { i. }\end{array}$ & $\begin{array}{l}\overline{8} \\
\overline{0} \\
0\end{array}$ & \begin{tabular}{l}
0 \\
\multirow{1}{0}{} \\
0 \\
0
\end{tabular} & $\begin{array}{l}\widetilde{0} \\
\text { ष् } \\
0\end{array}$ & 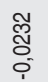 & $\begin{array}{l}8 \\
8 \\
0 \\
0\end{array}$ & $\begin{array}{l}\text { ơ } \\
0 \\
0 \\
0\end{array}$ & $\begin{array}{l}\text { đ్đ } \\
0 \\
0\end{array}$ & $\frac{\hat{f}}{\hat{L}}$ \\
\hline & $\theta$ & $\begin{array}{l}\stackrel{\mathbb{đ}}{0} \\
0\end{array}$ & & $\begin{array}{l}\stackrel{\widehat{O}}{d} \\
\stackrel{\Delta}{0}\end{array}$ & 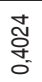 & 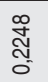 & \begin{tabular}{l}
$\stackrel{2}{0}$ \\
\hdashline \\
\end{tabular} & \begin{tabular}{l}
$\infty$ \\
$\stackrel{\circ}{0}$ \\
\hdashline \\
\end{tabular} & $\begin{array}{l}\text { Ñ } \\
\text { D్ల } \\
0\end{array}$ & $\begin{array}{l}\text { 号 } \\
\text { O. } \\
0\end{array}$ & 恕 & $\begin{array}{l}\stackrel{0}{0} \\
0 \\
0\end{array}$ & 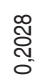 & 흥 & $\begin{array}{l}\stackrel{\mathrm{N}}{\mathrm{N}} \\
\end{array}$ & $\begin{array}{l}\infty \\
\stackrel{0}{0} \\
0 \\
0\end{array}$ \\
\hline & $\bigcup_{a}$ & $\begin{array}{l}\bar{Z} \\
\text { 足 } \\
0\end{array}$ & & 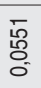 & $\begin{array}{l}\infty \\
\infty \\
\frac{\infty}{-\infty} \\
0\end{array}$ & $\begin{array}{l}\overline{1} \\
\text { o } \\
0 \\
0\end{array}$ & $\begin{array}{l}\mathscr{0} \\
\frac{0}{0}\end{array}$ & $\begin{array}{l}\frac{1}{0} \\
\overbrace{0}^{\circ} \\
\end{array}$ & $\begin{array}{l}\text { 8. } \\
0 \\
0\end{array}$ & $\begin{array}{l}\infty \\
0 \\
0 \\
0 \\
0\end{array}$ & \begin{tabular}{l}
$\widetilde{్}$ \\
\hdashline \\
0
\end{tabular} & $\begin{array}{l}\widetilde{\widetilde{J}} \\
\text { Oे } \\
\text { i. }\end{array}$ & $\begin{array}{l}\text { ஜू } \\
\stackrel{0}{0} \\
0\end{array}$ & 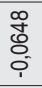 & $\begin{array}{l}\mathbb{Z} \\
\stackrel{0}{0} \\
0\end{array}$ & $\frac{0}{0}$ \\
\hline & $\bar{c}$ & 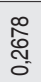 & & 艿 & $\begin{array}{l}\hat{0} \\
\stackrel{0}{0} \\
0\end{array}$ & $\begin{array}{l}\text { 怘 } \\
\text { 品 } \\
0.0\end{array}$ & $\begin{array}{l}\underset{J}{J} \\
\text { N } \\
0\end{array}$ & $\begin{array}{l}\text { o } \\
\text { o. } \\
\text { i. }\end{array}$ & \begin{tabular}{l}
$\overline{5}$ \\
\multirow{\sigma}{\sigma}{} \\
0
\end{tabular} & 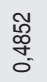 & $\begin{array}{l}\bar{E} \\
\overline{0} \\
0\end{array}$ & 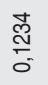 & 吕 & $\frac{\stackrel{m}{m}}{\frac{m}{0}}$ & 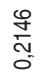 & $\frac{\mathscr{m}}{\stackrel{c}{c}}$ \\
\hline & 号 & 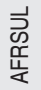 & 인 & $\stackrel{\infty}{\gtrless}$ & 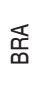 & \్ర & 퐁 & ठ․ & 苫 & 壳 & 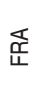 & 호 & $\Xi$ & $\frac{0}{5}$ & $\stackrel{\infty}{\not}$ & $\sum_{1}$ \\
\hline & 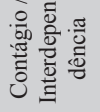 & - & & - & - & - & - & - & - & - & - & - & - & - & - & - \\
\hline 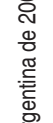 & 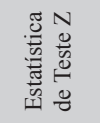 & 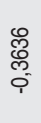 & & 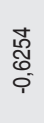 & 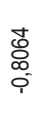 & $\begin{array}{l}\frac{8}{\circ} \\
0 \\
0\end{array}$ & $\frac{\mathfrak{1}}{\frac{1}{0}}$ & 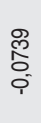 & 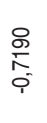 & 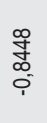 & 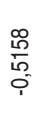 & 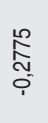 & 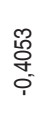 & $\begin{array}{l}\text { o } \\
\text { o. } \\
\text { c. } \\
\end{array}$ & 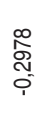 & $\frac{8}{\stackrel{0}{0}}$ \\
\hline 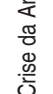 & 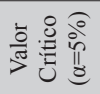 & ه্ঠ & & \& & \& & $\begin{array}{l}\stackrel{8}{\circ} \\
\stackrel{-}{-}\end{array}$ & $\begin{array}{l}8 \\
\stackrel{8}{\circ} \\
\stackrel{-}{-}\end{array}$ & $\begin{array}{l}8 \\
\text { o } \\
\stackrel{-}{-}\end{array}$ & 兽 & $\begin{array}{l}8 \\
\stackrel{8}{\circ} \\
\stackrel{-}{-}\end{array}$ & \& & ষ্ণ & $\begin{array}{l}\stackrel{8}{\circ} \\
\stackrel{-}{-}\end{array}$ & \& & $\begin{array}{l}\stackrel{8}{\circ} \\
\stackrel{-}{-}\end{array}$ & $\begin{array}{l}\stackrel{8}{\circ} \\
\stackrel{-}{-}\end{array}$ \\
\hline 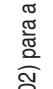 & 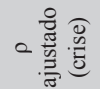 & 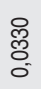 & & $\begin{array}{l}\mathscr{ల} \\
\text { Ö } \\
0.0\end{array}$ & $\frac{\tilde{m}}{\stackrel{c}{0}}$ & $\begin{array}{l}\widetilde{N} \\
\text { Oֶ. } \\
0\end{array}$ & $\frac{\widetilde{\sigma}}{0}$ & 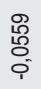 & $\begin{array}{l}\bar{y} \\
\text { 今े } \\
\text { O. }\end{array}$ & $\begin{array}{l}8 \\
\text { 웅 } \\
0\end{array}$ & $\begin{array}{l}\stackrel{0}{\circ} \\
\text { O. } \\
0.0\end{array}$ & $\begin{array}{l}\bar{\sigma} \\
\stackrel{5}{0} \\
0 \\
\end{array}$ & $\begin{array}{l}\text { 足 } \\
\text { O. } \\
0\end{array}$ & 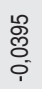 & $\begin{array}{l}\stackrel{\circ}{0} \\
\text { O. } \\
0\end{array}$ & $\frac{0}{0}$ \\
\hline 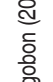 & $U_{a}$ & $\begin{array}{l}\bar{Z} \\
\text { 员 } \\
0\end{array}$ & & $\begin{array}{l}\bar{\delta} \\
\text { 员 } \\
0\end{array}$ & $\begin{array}{l}\infty \\
\infty \\
\infty \\
0 \\
0\end{array}$ & $\begin{array}{l}\overline{1} \\
\text { o } \\
0\end{array}$ & $\begin{array}{l}\stackrel{0}{0} \\
\frac{0}{0}\end{array}$ & $\begin{array}{l}+ \\
\frac{7}{8} \\
\\
\end{array}$ & $\begin{array}{l}8 \\
0 \\
0 \\
0.0\end{array}$ & $\begin{array}{l}\infty \\
\vdots \\
0 \\
0 \\
0\end{array}$ & \begin{tabular}{l}
$\widetilde{్}$ \\
\hdashline \\
\hdashline
\end{tabular} & 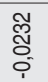 & $\begin{array}{l}\mathscr{0} \\
\text { ஜ्ष } \\
0.0\end{array}$ & $\begin{array}{l}\text { ơ } \\
\stackrel{0}{\circ} \\
0 \\
\end{array}$ & 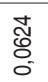 & $\frac{\stackrel{0}{0}}{\frac{0}{0}}$ \\
\hline 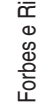 & 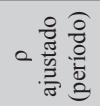 & $\begin{array}{l}\text { \% } \\
\text { : } \\
0\end{array}$ & & $\begin{array}{l}\infty \\
: \\
0 \\
0 \\
0\end{array}$ & $\frac{\infty}{\infty}$ & $\frac{\infty}{0}$ & $\frac{8}{\frac{p}{0}}$ & 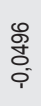 & $\begin{array}{l}\tilde{0} \\
\frac{0}{0}\end{array}$ & $\underset{\substack{\infty \\
\frac{\infty}{0}}}{0}$ & $\begin{array}{l}\frac{\infty}{0} \\
0 \\
0 \\
0\end{array}$ & $\begin{array}{l}\text { 范 } \\
\text { : }\end{array}$ & $\begin{array}{l}\tilde{0} \\
0 \\
0 \\
0\end{array}$ & $\begin{array}{l}\text { ô. } \\
\text { : } \\
\text { i. }\end{array}$ & $\begin{array}{l}\text { 范 } \\
0 \\
0\end{array}$ & $\begin{array}{l}\stackrel{0}{\circ} \\
\circ \\
0\end{array}$ \\
\hline $\begin{array}{l}\frac{0}{0} \\
\frac{0}{0} \\
\frac{3}{0} \\
0 \\
0\end{array}$ & $=\frac{\frac{o}{0}}{.0}$ & $\frac{\text { 웜 }}{0}$ & & $\frac{\frac{10}{5}}{\frac{10}{0}}$ & 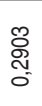 & $\frac{\substack{N \\
0}}{0}$ & $\begin{array}{l}\mathscr{D}_{0} \\
\frac{\infty}{0}\end{array}$ & 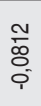 & $\begin{array}{l}8 \\
0 \\
0 \\
0 \\
0\end{array}$ & $\frac{\mathscr{2}}{\stackrel{2}{\circ}}$ & $\frac{\stackrel{m}{m}}{\stackrel{m}{0}_{-}}$ & $\begin{array}{l}\stackrel{0}{\circ} \\
\stackrel{\circ}{\circ} \\
0\end{array}$ & 总 & 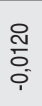 & $\begin{array}{l}\mathscr{0} \\
\frac{0}{0} \\
0\end{array}$ & $\frac{\tilde{N}}{\tilde{\sigma}}$ \\
\hline 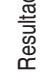 & $\stackrel{n}{\tilde{\tilde{E}}}$ & 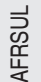 & 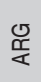 & 安 & 畄 & Z્ર & 퐁 & రె & 离 & 胥 & $\underset{\mathbb{4}}{\mathbb{\leftrightarrow}}$ & 오 & $\Xi$ & $\frac{0}{5}$ & $\stackrel{\infty}{\stackrel{\sim}{\alpha}}$ & $\sum_{k}$ \\
\hline
\end{tabular}




\begin{tabular}{|c|c|c|c|c|c|c|c|c|c|c|c|c|c|c|c|c|}
\hline \multirow{10}{*}{ 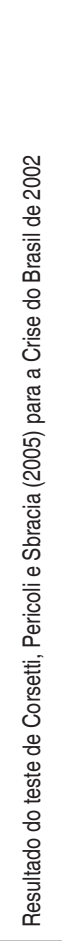 } & 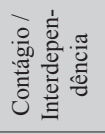 & - & - & - & & - & - & - & - & - & - & - & - & - & - & - \\
\hline & 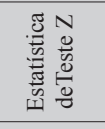 & 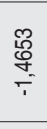 & 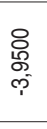 & 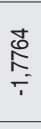 & & 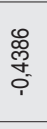 & $\begin{array}{l}\bar{o} \\
\text { ơ⿱ } \\
0 \\
0\end{array}$ & $\stackrel{\frac{m}{\infty}}{\stackrel{m}{g}}$ & 累 & 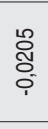 & $\frac{\stackrel{\infty}{\%}}{\stackrel{\leftrightarrow}{\sigma}}$ & ్ㅠㅇ & $\begin{array}{l}\hat{N} \\
\hat{N} \\
\hat{i}\end{array}$ & $\begin{array}{l}\hat{0} \\
0 \\
0 \\
\end{array}$ & 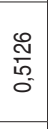 & $\begin{array}{c}\text { Na } \\
\text { o. } \\
\text { o. }\end{array}$ \\
\hline & 离递总 & $\begin{array}{l}8 \\
\stackrel{\circ}{\circ} \\
-\end{array}$ & $\stackrel{8}{\circ}$ & $\begin{array}{l}8 \\
\stackrel{8}{\circ} \\
-\end{array}$ & & ষ্ণ & $\begin{array}{l}\stackrel{8}{\circ} \\
- \\
-\end{array}$ & $\begin{array}{l}\stackrel{8}{\circ} \\
\stackrel{-}{-}\end{array}$ & : & $\stackrel{8}{\circ}$ & \&. & 。্̊ & 吕 & $\stackrel{8}{\circ}$ & 吕 & $\begin{array}{l}\stackrel{8}{\circ} \\
\stackrel{-}{-}\end{array}$ \\
\hline & $\tilde{O}$ & $\frac{m}{8}$ & 임 & 응 & & $\begin{array}{l}\frac{m}{8} \\
0 \\
0\end{array}$ & $\begin{array}{l}0 \\
\frac{0}{8} \\
0\end{array}$ & $\begin{array}{l}\frac{1}{8} \\
0 \\
0\end{array}$ & $\begin{array}{l}\frac{m}{8} \\
\stackrel{0}{\circ} \\
0\end{array}$ & 응 & $\begin{array}{l}m \\
0 \\
0\end{array}$ & 잉 & $\begin{array}{l}\frac{m}{8} \\
\frac{0}{0} \\
0\end{array}$ & $\begin{array}{l}\frac{m}{8} \\
\frac{0}{0} \\
\end{array}$ & $\begin{array}{l}\frac{m}{8} \\
0 \\
0\end{array}$ & 웅 \\
\hline & 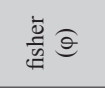 & $\begin{array}{l}\text { òे } \\
\text { ì } \\
\text { o. }\end{array}$ & 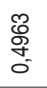 & $\begin{array}{l}\infty \\
\stackrel{\sigma}{q}\end{array}$ & & 吕 & $\begin{array}{l}\text { ơ } \\
\text { ơ } \\
\text { o }\end{array}$ & $\begin{array}{l}\frac{\text { v }}{0} \\
0 \\
0\end{array}$ & $\begin{array}{l}\frac{2}{2} \\
\frac{1}{\sigma} \\
0\end{array}$ & 艿 & 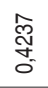 & 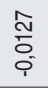 & $\begin{array}{l}\text { \% } \\
\text { o. } \\
0 \\
0\end{array}$ & 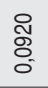 & $\begin{array}{l}\frac{2}{0} \\
\frac{0}{0}\end{array}$ & $\begin{array}{l}\hat{s} \\
\text { o. } \\
0\end{array}$ \\
\hline & 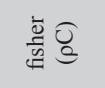 & $\begin{array}{l}\bar{T} \\
\stackrel{0}{0} \\
0\end{array}$ & $\begin{array}{l}\stackrel{0}{m} \\
\frac{m}{0}\end{array}$ & 足 & & $\begin{array}{l}\mathscr{0} \\
\stackrel{0}{0} \\
\stackrel{0}{0}\end{array}$ & 永 & $\begin{array}{l}8 \\
\text { 음 } \\
-\end{array}$ & 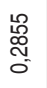 & 荧 & $\begin{array}{l}\bar{\pi} \\
\underset{\infty}{0} \\
0\end{array}$ & 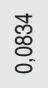 & $\begin{array}{l}\text { đ్̃ } \\
\text { ల్ } \\
\text { o. }\end{array}$ & $\begin{array}{l}: 0 \\
0 \\
0 \\
0\end{array}$ & 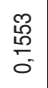 & $\begin{array}{l}\stackrel{\leftrightarrow}{\circ} \\
\stackrel{\circ}{\circ}\end{array}$ \\
\hline & $\theta$ & $\begin{array}{l}\text { ळ } \\
\stackrel{0}{\circ} \\
\end{array}$ & 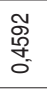 & 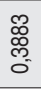 & & \begin{tabular}{l}
$\infty$ \\
\multirow{\Im}{*}{} \\
ó
\end{tabular} & $\begin{array}{l}\stackrel{8}{0} \\
\text { o } \\
0 \\
0\end{array}$ & 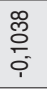 & 总 & $\begin{array}{l}\text { J } \\
\text { ơ } \\
0 \\
\end{array}$ & $\begin{array}{l}8 \\
\text { ơ } \\
\text { ó }\end{array}$ & $\begin{array}{l}\text { Nิ } \\
\vdots \\
- \\
\end{array}$ & 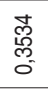 & 응 & 응 & $\begin{array}{l}\mathscr{8} \\
\stackrel{8}{0} \\
0\end{array}$ \\
\hline & U্口 & $\begin{array}{l}8 \\
8 \\
0 \\
0\end{array}$ & $\frac{\infty}{\mathrm{d}}$ & $\stackrel{\mathscr{I}}{\stackrel{\sim}{\sim}}$ & & న్ల & 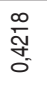 & $\begin{array}{l}8 \\
\text { ․․ } \\
\\
\end{array}$ & 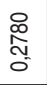 & 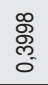 & $\begin{array}{l}\text { d. } \\
\text { N } \\
0\end{array}$ & $\begin{array}{l}\widetilde{0} \\
\stackrel{0}{0} \\
\text { ○. }\end{array}$ & \begin{tabular}{l} 
ֻू్ \\
N̦ \\
\hdashline
\end{tabular} & $\begin{array}{l}\text { Oे } \\
\stackrel{0}{0} \\
0\end{array}$ & 息 & $\begin{array}{l}\bar{\infty} \\
\stackrel{\circ}{\circ} \\
\text { ?. }\end{array}$ \\
\hline & $t_{a}$ & $\frac{}{\frac{0}{1}}$ & 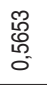 & ஜூ & & $\underset{\widetilde{N}}{\stackrel{N}{f}}$ & 交 & $\begin{array}{l}\text { : } \\
: 0 \\
\text { : }\end{array}$ & 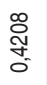 & 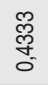 & $\begin{array}{l}\hat{\text { o }} \\
\text { ơ } \\
\text { - }\end{array}$ & $\begin{array}{l}\text { पे } \\
\vdots \\
0 \\
0\end{array}$ & $\begin{array}{l}\text { ్్ㅇ } \\
\text { O } \\
0\end{array}$ & $\begin{array}{l}\infty \\
\stackrel{\infty}{\rho} \\
0 \\
0 \\
0\end{array}$ & $\begin{array}{l}\text { 今. } \\
\text { O. } \\
\text { O. }\end{array}$ & $\begin{array}{l}\text { 용 } \\
0 \\
0\end{array}$ \\
\hline & 竎 & 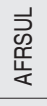 & 感 & $\stackrel{0}{\mathcal{Z}}$ & 嵒 & Z્ડ & 퐁 & ठ્ઠ & 号 & 蛋 & 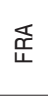 & 오 & $\Xi$ & 足 & $\stackrel{\mathscr{D}}{\underset{\sim}{2}}$ & $\sum_{k}$ \\
\hline \multirow{8}{*}{ 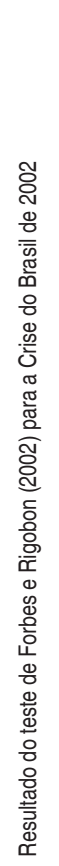 } & 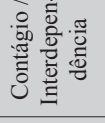 & - & - & - & & - & - & - & - & - & - & - & - & - & - & - \\
\hline & 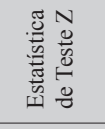 & 孞 & $\begin{array}{l}\frac{1}{0} \\
\frac{0}{5} \\
\frac{1}{1}\end{array}$ & $\begin{array}{l}\overline{1} \\
0 \\
0 \\
0 \\
0\end{array}$ & & ০্ల్ల & $\frac{\text { 妾 }}{0}$ & 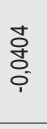 & $\begin{array}{l}\bar{\delta} \\
\text { ơ } \\
\text { o. }\end{array}$ & $\frac{\infty}{\frac{\infty}{0}}$ & $\begin{array}{l}\text { ô } \\
0 \\
0 \\
0 \\
1\end{array}$ & 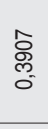 & $\frac{8}{\frac{8}{6}}$ & $\begin{array}{l}\text { 茴 } \\
0 \\
0\end{array}$ & $\stackrel{\infty}{\bar{m}}$ & 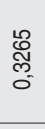 \\
\hline & 紊总 总 & ষ্ণ & 条 & \& & & ه্ঠ & $\begin{array}{l}\stackrel{8}{\circ} \\
\stackrel{-}{-}\end{array}$ & $\begin{array}{l}\stackrel{8}{\circ} \\
\stackrel{\circ}{-}\end{array}$ & $\begin{array}{l}8 \\
8 \\
\stackrel{8}{-}\end{array}$ & $\begin{array}{l}8 \\
\stackrel{8}{\circ} \\
-\end{array}$ & 용 & 용 & $\begin{array}{l}\stackrel{8}{\circ} \\
\stackrel{-}{-}\end{array}$ & $\stackrel{8}{\stackrel{\circ}{\circ}}$ & \& & $\begin{array}{l}\stackrel{8}{\circ} \\
\stackrel{-}{-}\end{array}$ \\
\hline & 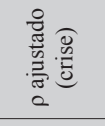 & $\begin{array}{l}\text { o. } \\
\text { o. } \\
0 \\
0\end{array}$ & $\frac{\hat{\mathrm{N}}}{\mathrm{O}}$ & & & $\begin{array}{l}\frac{\omega}{20} \\
\stackrel{0}{0} \\
0\end{array}$ & $\begin{array}{l}\text { O్. } \\
\text { o } \\
0 \\
0\end{array}$ & 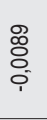 & 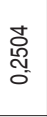 & $\begin{array}{l}\widetilde{c} \\
\text { ల్ } \\
0 \\
0\end{array}$ & $\begin{array}{l}\hat{N} \\
\stackrel{N}{N} \\
0\end{array}$ & $\begin{array}{l}\frac{7}{0} \\
\text { O } \\
0\end{array}$ & 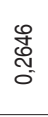 & 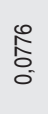 & 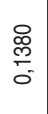 & $\frac{\frac{\pi}{\sigma}}{0}$ \\
\hline & U. & $\begin{array}{l}8 \\
8 \\
0\end{array}$ & $\frac{\text { ơ }}{\frac{\mathrm{d}}{0}}$ & $\stackrel{\overbrace{}}{\mathscr{~}}$ & & $\underset{\infty}{\infty}$ & $\stackrel{\infty}{i}$ & 응 & $\stackrel{\infty}{\circledR}$ & $\begin{array}{l}\text { o. } \\
\text { o } \\
\text { o. }\end{array}$ & 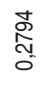 & $\begin{array}{l}\widetilde{0} \\
\text { Oू. } \\
\text { O. }\end{array}$ & 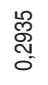 & $\begin{array}{l}\hat{0} \\
\ddot{\circ} \\
0\end{array}$ & $\begin{array}{l}\frac{5}{6} \\
\frac{0}{0}\end{array}$ & $\begin{array}{l}\frac{1}{0} \\
\stackrel{0}{0} \\
\end{array}$ \\
\hline & 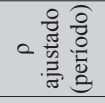 & 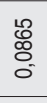 & 莡 & 危 & & $\underset{N}{\hat{N}}$ & 吕 & $\begin{array}{l}\text { षे } \\
\text { ष्. }\end{array}$ & $\begin{array}{c}\widehat{0} \\
\text { ơ } \\
\text { o }\end{array}$ & 胥 & 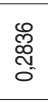 & $\begin{array}{l}\infty \\
\stackrel{0}{\delta} \\
0\end{array}$ & 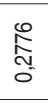 & $\begin{array}{l}\text { §o } \\
0 \\
0 \\
0\end{array}$ & $\frac{\stackrel{L}{\circ}}{\frac{1}{0}}$ & $\frac{\stackrel{2}{\circ}}{\frac{0}{\circ}}$ \\
\hline & a $\frac{\hat{\sigma}}{0}$ & $\begin{array}{l}\hat{\ddot{O}} \\
\ddot{\circ}\end{array}$ & 惫 & $\begin{array}{l}\text { 勇 } \\
\underset{0}{0} \\
0\end{array}$ & & 粱 & 产 & $\begin{array}{l}: 0 \\
: \\
0 \\
\end{array}$ & $\frac{\frac{9}{0}}{\frac{9}{0}}$ & 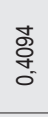 & $\frac{\bar{y}}{\bar{c}}$ & 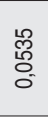 & $\begin{array}{l}0 \\
0 \\
0 \\
0 \\
0\end{array}$ & $\begin{array}{l}\text { 잉 } \\
0 \\
0 \\
0\end{array}$ & 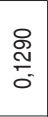 & 雇 \\
\hline & $\stackrel{\mathscr{u}}{\tilde{\tilde{z}}}$ & 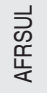 & 品 & $\stackrel{N}{\gtrless}$ & 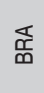 & ડ્ડ & $\overline{\bar{J}}$ & ठ․ & $\begin{array}{l}\frac{n}{5} \\
\text { na }\end{array}$ & 豈 & 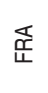 & 호 & $\leqq$ & $\frac{0}{5}$ & $\stackrel{\mathscr{N}}{\underset{\sim}{2}}$ & $\sum_{k}$ \\
\hline
\end{tabular}




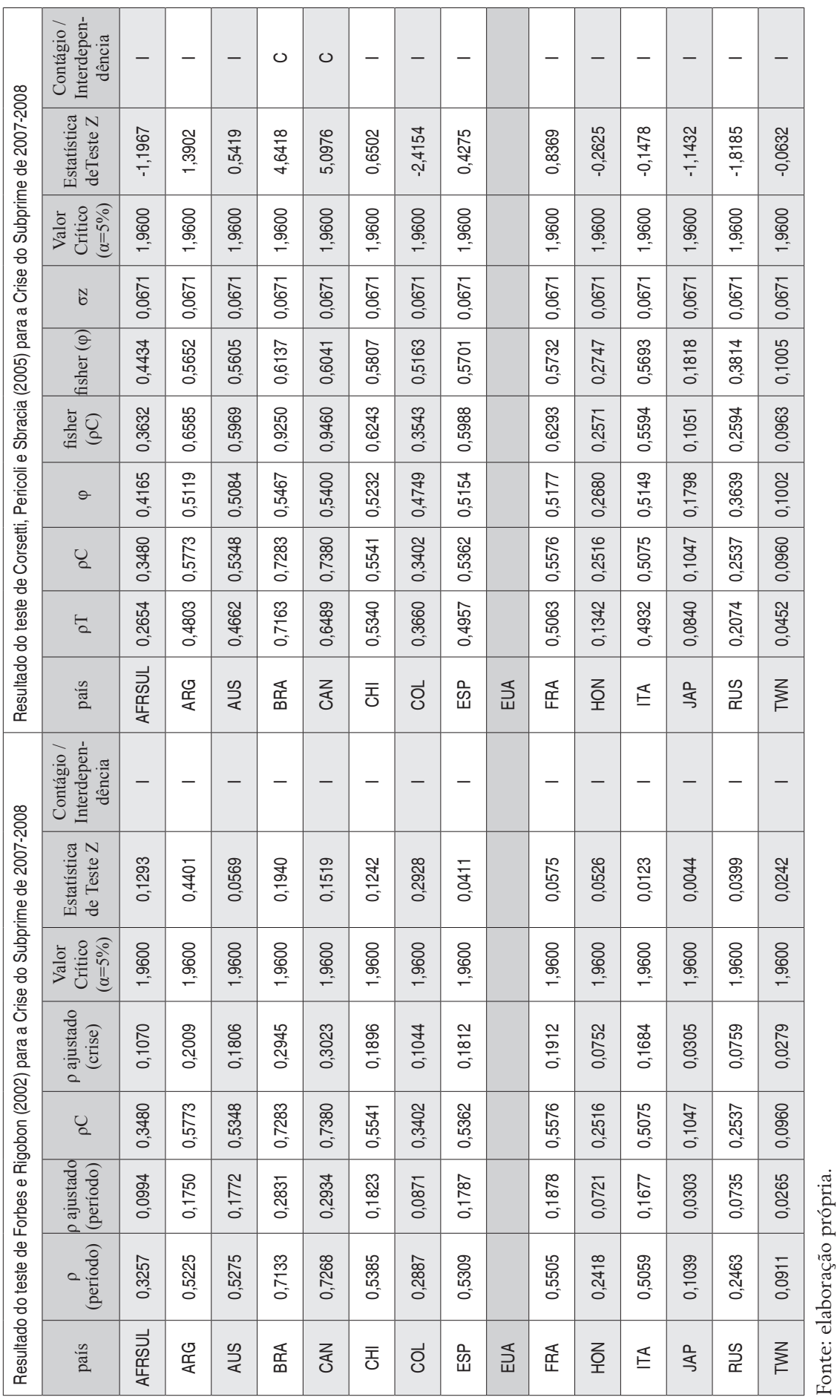


Corroborando os comentários de Neal e Weidenmier (2002), é possível concluir que a crise asiática é o principal exemplo de efeito contágio estudado, comparativamente às outras crises analisadas. Esta afirmação deve ser ponderada pelo momento vivenciado pela economia internacional. A correlação entre os países na época era consideravelmente baixa durante o período de tranquilidade, uma vez que muitos deles ainda não apresentavam uma abertura econômica significativa. Além disso, os modelos que avaliavam os riscos dos investimentos eram simplórios e timidamente utilizados. Os investimentos nos países emergentes asiáticos eram feitos à revelia, na espera de ganhos anormais insustentáveis. Vale ressaltar que o desenvolvimento das instituições privadas asiáticas deu-se, principalmente, através de investimentos estrangeiros, intensificando assim as relações internacionais da Ásia com o resto do mundo e aumentando a vulnerabilidade dos países frente à criação de um relevante canal de transmissão de choques.

Outro ponto importante que pode ser extraído dos resultados é que, com exceção de Canadá, Espanha e França, os países contagiados pela crise asiática foram países emergentes. Esta conclusão vai ao encontro do histórico sobre a crise russa de 1998, a partir do que esta crise, assim como a crise brasileira de 1999, são vistas, por alguns autores, como consequências da crise asiática, uma vez que, após a crise de confiança instalada na Ásia, os investidores internacionais passaram a rever suas posições em outros países emergentes e a restringir crédito a economias que eram vistas como semelhantes em risco. Esse contexto justifica a falta de indícios de efeito contágio da crise russa de 1998. Dessa forma, esse evento pode ser considerado como um efeito de turbulências restrito a este país ou, mais provável, como uma profunda consequência do efeito contágio originado em Hong Kong um ano antes.

Os indícios de contágio identificados durante a crise brasileira de 1999 também estão de acordo com as expectativas levantadas por outros autores. De acordo com os resultados de Corsetti, Pericoli e Sbracia (2005), a crise brasileira, que culminou com o abandono do sistema cambial vigente, gerou quebras na estrutura de transmissão de choques existente com Argentina, Canadá, Chile e Estados Unidos. Segundo Murta, Brasil e Samohyl (2003), as crises asiática e russa contribuíram para acelerar a desvalorização do câmbio brasileiro, ocasionando queda no preço das commodities e redução do 
crédito externo. O país tentou manter o regime de câmbio vigente e os juros altos, atrativos para os investidores estrangeiros, às custas do aumento da dívida externa e privatizações, tornando suas relações internacionais vulneráveis. Estas iniciativas brasileiras, associadas aos eventos do Apagão Elétrico e superávit comercial brasileiro nas relações comerciais com a Argentina, tornaram insustentável a manutenção do regime argentino de paridade com o dólar, levando à desvalorização do câmbio desse país, assim como ao decreto de moratória da dívida externa, culminando na crise argentina de 2001.

O episódio da bolha da Internet apresenta, segundo a metodologia de Corsetti, Pericoli e Sbracia (2005), indícios de efeito contágio entre Estados Unidos e África do Sul, Argentina e Canadá, sendo este último, à época, referência na criação de softwares livres.

As consequências do ataque terrorista ao World Trade Center em 11 de setembro de 2001 se alastraram em forma de contágio para Austrália, Brasil, Canadá, Chile, Espanha e França, impactando, principalmente, o turismo e as relações comerciais entre esses países. Após o ataque, a economia norte-americana destinou vultosos recursos à chamada Guerra ao Terror, com o objetivo de dissolver a rede terrorista responsável pelos ataques, a Al-Qaeda e seu líder Osama Bin Laden, investindo suas reservas na indústria bélica, iniciativa esta veementemente criticada pela população.

O período de 1999 a 2002 foi marcado por turbulências importantes nos países sul-americanos, principalmente na Argentina e Brasil. A dificuldade de acesso a recursos internacionais inviabilizava as adequações de suas iniciativas às exigências dos países e organizações detentoras de crédito, culminando numa série de episódios de choques financeiros oriundos dessas economias. Devido à forte relação existente entre Brasil e Argentina, devido tanto a vínculos comerciais quanto à proximidade regional, num primeiro momento, espera-se que exista uma relação de interdependência e que esta se mantenha em momentos de crise. Entretanto, no episódio de 1999, os choques foram fortes o suficiente para quebrar a estrutura de transmissão de movimentos financeiros e contagiar a economia argentina. Já a crise brasileira de 2002 apresentou características estritamente particulares, justificando a não existência de indícios de efeito contágio. 
Por fim, a crise do Subprime de 2007, originada nos Estados Unidos, apresentou indícios de contágio em dois outros países: Brasil e Canadá. Em todos os outros países da amostra, a estrutura de transmissão de choques manteve-se constante e o aumento nas correlações manteve-se em um intervalo esperado. Os resultados encontrados são corroborados por testes de robustez (Tabela 6). Conforme mencionado anteriormente, a escolha dos períodos de tranquilidade e crise e a sobreposição de datas podem impactar os resultados.

Dessa forma, optou-se por verificar a sensibilidade dos testes a essas variações. Os resultados comparados encontram-se abaixo. As principais discrepâncias estão na crise da Ásia, em que o teste de robustez para a metodologia de Corsetti, Pericoli e Sbracia (2005) não indicou efeito contágio para Canadá e Chile; na crise brasileira de 1999, em que o teste de robustez indicou efeito contágio apenas entre Brasil e Argentina; na bolha da Internet, cujo teste de robustez para Forbes e Rigobon (2002) indicou efeito contágio para a Argentina; para o ataque terrorista de 11 de setembro de 2001 o teste de robustez não indicou efeito contágio para o Brasil e para o Chile; e, por fim, na crise brasileira de 2002, o teste de robustez indicou efeito contágio para a África do Sul.

A partir dos resultados obtidos, verifica-se a importância das adequações sugeridas por Corsetti, Pericoli e Sbracia (2005) em seu propósito de identificar evidências do efeito contágio entre as economias após períodos de turbulência, corroborando as críticas dos autores ao trabalho de Forbes e Rigobon (2002), quando afirmam que o ajuste sugerido por esses não é inteiramente adequado à captura dos efeitos adversos dos choques financeiros. 
Tabela 6 - Teste de robustez

\begin{tabular}{|c|c|c|c|c|c|}
\hline \multicolumn{6}{|c|}{ Tabela Resumo } \\
\hline \multirow{3}{*}{ Crises } & \multicolumn{5}{|c|}{ Teste de Robustez Mudando as Datas de Início e Final dos Períodos de T e C } \\
\hline & \multicolumn{2}{|c|}{$\begin{array}{l}\text { Número de países com indícios } \\
\text { de contágio }\end{array}$} & \multirow[b]{2}{*}{ Países contagiados } & \multicolumn{2}{|c|}{$\begin{array}{l}\text { Número de países com indícios } \\
\text { de contágio }\end{array}$} \\
\hline & $\begin{array}{l}\text { Forbes e Rigobon } \\
\qquad(2002)\end{array}$ & $\begin{array}{l}\text { Corsetti, Pericoli } \\
\text { e Sbracia (2005) }\end{array}$ & & $\begin{array}{l}\text { Forbes e Rigobon } \\
\qquad(2002)\end{array}$ & $\begin{array}{l}\text { Corsetti, Pericoli } \\
\text { e Sbracia (2005) }\end{array}$ \\
\hline Crise da Ásia (1997) & 0 & 6 & $\begin{array}{l}\text { África do Sul, Austrá- } \\
\text { lia, Espanha, França, } \\
\text { Japão e Rússia }\end{array}$ & 0 & 8 \\
\hline Crise da Rússia (1998) & 0 & 0 & & 0 & 0 \\
\hline Crise Brasileira (1999) & 0 & 1 & Argentina & 0 & 4 \\
\hline Bolha da Internet (2000) & 1 & 3 & $\begin{array}{c}\text { Argentina / África } \\
\text { do Sul, Argentina e } \\
\text { Canadá }\end{array}$ & 0 & 3 \\
\hline 11 de setembro (2001) & 0 & 5 & $\begin{array}{c}\text { Austrália, Canadá, } \\
\text { Espanha, França } \\
\text { e ltália }\end{array}$ & 0 & 6 \\
\hline Crise Argentina (2001) & 0 & 0 & & 0 & 0 \\
\hline Crise Brasileira (2002) & 0 & 1 & África do Sul & 0 & 0 \\
\hline Crise do Subprime & 0 & 2 & Brasil e Canadá & 0 & 2 \\
\hline
\end{tabular}

Fonte: elaboração própria.

\section{Considerações Finais}

Há muito o efeito contágio vem assumindo destaque nos estudos acerca das crises financeiras, dando origem a uma preocupação crescente em se definir e encontrar metodologias cada vez melhores para identificar a sua ocorrência. Os estudos sobre o efeito contágio assumem diversas vertentes empíricas, como a análise dos canais de transmissão de choques, o sentido da transmissão de volatilidade entre as economias, mecanismos de antecipação de impactos financeiros no intuito de tomar ações político-econômicas que suavizem o efeito contágio, entre outros.

Os resultados apresentados por este trabalho levantam questões importantes a respeito da relação conceito-metodologia. O conceito de contágio utilizado neste trabalho, onde este é visto como uma quebra estrutural do mecanismo de transmissão de choques preexistente, permite a utilização da correlação dos retornos como uma proxy para medir inter-relação entre as economias dos países. 
É esperado então que esta inter-relação se intensifique durante o período de crises financeiras, ocasionando um aumento dos coeficientes de correlação.

De acordo com outro conceito de contágio utilizado pela literatura, o efeito de transmissão de choques também pode ser medido através da análise da volatilidade dos retornos dos países. O aumento na volatilidade dos países também é um indício da transmissão de turbulências. Forbes e Rigobon (2002), assim como Corsetti, Pericoli e Sbracia (2005), levantam questões a respeito da influência do aumento da volatilidade nos coeficientes de correlação. Caso o aumento da correlação seja analisado de forma percentual ou absoluta, existe um viés em aceitar a hipótese de efeito contágio. Para eliminar esse viés, os autores sugerem ajustes a serem feitos nos coeficientes de correlação que adequem os retornos a problemas de heterocedasticidade.

Este trabalho cumpriu seus objetivos ao utilizar uma das reconhecidas abordagens sobre o efeito contágio, presente no estudo de Corsetti, Pericoli e Sbracia (2005), para oito episódios de turbulências financeiras internacionalmente impactantes. Além disso, aplicou-se também o ajuste sugerido por Forbes e Rigobon (2002) no intuito de verificar indícios das críticas comentadas pelos primeiros autores a respeito de vieses em rejeitar a hipótese de contágio presentes nessa segunda abordagem.

Os resultados encontrados a partir da aplicação da metodologia de Forbes e Rigobon (2002) vão ao encontro das críticas levantadas por Corsetti, Pericoli e Sbracia (2005). Nos oito episódios de crises analisados para quinze países da amostra, não foram encontrados indícios de efeito contágio seguindo a metodologia de Forbes e Rigobon (2002). Já no caso da metodologia de Corsetti, Pericoli e Sbracia (2005), foram encontradas evidências de efeito contágio durante a maior parte das crises financeiras, com exceção da crise russa de 1998, crise argentina de 2001 e crise brasileira de 2002.

Esses resultados também estão de acordo com os trabalhos de Holanda e Correa (2003), Corsetti, Pericoli e Sbracia (2005) e Billio e Caporin (2010). Esses autores evidenciam contágio significante durante a crise asiática de 1997, onde há indícios de aumento significante nas correlações dos Bradies Bonds e do mercado de capitais 
nesse período, podendo-se apontar França, Brasil, Estados Unidos e Japão como os países mais contagiados, que sofrem impactos em todos os estudos analisados.

No caso da crise russa de 1998, os resultados deste estudo divergem dos de Guidugli (2005), Holanda e Correa (2003) e Edwards e Susmel (2001). Nesses estudos, há indícios de efeito contágio da crise da Rússia, o que não foi identificado pela metodologia de Corsetti, Pericoli e Sbracia (2005), levando-se a considerar a crise russa como um aprofundamento da crise asiática de 1997 naquele país.

Em se tratando da crise brasileira de 1999, os resultados deste estudo corroboram os de Edwards e Susmel (2001) e Holanda e Correa (2003), ao considerar a disseminação do choque principalmente para a Argentina, fato este que salienta a influência do comércio como um canal de transmissão de turbulências, assim como em Eichengreen, Rose e Wyplosz (1996).

De uma forma sintetizada, pode-se concluir que, das crises analisadas, a asiática mostrou-se a mais contagiosa, devido ao momento internacional à época. As economias não estavam tão integradas como atualmente e as turbulências financeiras fizeram com que novas ferramentas que visam à redução da vulnerabilidade financeira e internacional fossem criadas. Ao longo do tempo, apesar da severidade das turbulências, essas se tornaram menos contagiosas, como no caso dos ataques terroristas de 11 de setembro de 2001 e do Subprime de 2007.

Outro ponto relevante é a capilaridade da distribuição dos choques. Quando os eventos financeiros foram originados em países desenvolvidos, como os Estados Unidos, as crises apresentaram indícios de contágio, como no caso da Bolha da Internet de 2000, ataques terroristas de 11 de setembro de 2001 e crise do Subprime de 2007. No caso de crises originadas em países subdesenvolvidos, apenas a crise da Ásia de 1997 e a crise brasileira de 1999 contagiaram outros países, o que corrobora as evidências de Eichengreen, Rose e Wyplosz (1996). O fato de episódios como a crise da Rússia de 1998, a crise argentina de 2001 e a crise brasileira de 2002 não terem apresentado indícios de efeito contágio pode ser justificado de duas formas: a primeira pode considerar que esses eventos são consequências profundas de turbulências anteriores que desencadearam 
crises nesses países. A segunda justificativa diz respeito ao sentido da transmissão do choque, ou seja, não há indícios de efeito contágio, pois os choques se restringiram a estas economias, não se mostrando significativos para as demais.

Uma das limitações do presente trabalho é a falta de métodos científicos para identificar os canais de transmissão dos choques. Conforme mencionado anteriormente por Eichengreen, Rose e Wyplosz (1996), esse tipo de análise é relevante, pois permite análises mais profundas das razões do efeito contágio, assim como abre espaço para discussões sobre a vulnerabilidade do país afetado frente à economia internacional dos países.

Outro ponto interessante para estudos futuros seria a adoção de outras metodologias de teste para o efeito contágio que não utilizassem a correlação como proxy, mas sim modelos que capturem o comportamento da volatilidade e sua direção internacional. Por fim, vale destacar a importância do estudo do efeito contágio em todas as vertentes político-econômicas, principalmente para os tomadores de decisão e investidores.

\section{Referências}

BERGMANN, Daniel Reed; SAVOIA, José Roberto; SAITO; André Taue; CONTANI, Eduardo. Contagion effects of the US Subprime Crisis on Latin American and European Union Stock Markets. In: BALAS - The Business Association of Latin American Studies Conference, Barcelona, Spain, 2010.

BILLIO, Monica; CAPORIN, Massimiliano. Market linkages, variance spillovers, and correlation stability: Empirical evidence of financial contagion. Computational Statistics and Data Analysis, 54, p. 2443-2458, 2010.

CORRAR, Luiz J.; PAULO, Edilson; DIAS FILHO, José Maria (Org.). Análise Multivariada: para os cursos de Administração, Ciência Contábeis e Economia. São Paulo: Atlas, 2007.

CORSETTI, Giancarlo; PERICOLI, Marcello Pericoli; SBRACIA, Massimo. Some contagion, some interdependence: More pitfalls in tests of financial contagion. Journal of International Money and Finance, 24 (8), pp. 1177-1199, 2005.

DORNBUSCH, Rudiger; PARK, Yung Chul; CLAESSENS, Stijn. Contagion: Understanding How It Spreads. The World Bank Research Observer, vol.5, n.2, p.177-197, August, 2000.

EDWARDS, Sebastian; SUSMEL, Raul. Volatility Dependence and Contagion in Emerging Equity Markets. Cambridge: NBER Working Paper, n.8506, October, 2001.

EICHENGREEN, Barry; ROSE, Andrew K.; WYPLOSZS, Charles. Contagious Currency Crises. NBER Working Paper, n. 5681, July, 1996.

FÁVERO, Luiz Paulo et al. Análise de Dados: Modelagem Multivariada para Tomada de Decisões. Rio de Janeiro: Elsevier, 2009. 
FORBES, Kristin; RIGOBON, Roberto. No Contagion, Only Interdependence: Measuring Stock Market Comovements. Journal of Finance, v.57, n.5, October, 2002.

GUIDUGLI, Sidival Tadeu. Análise multivariada do efeito contágio no episódio de ataque especulativo e crise cambial envolvendo o Brasil, a Rússia e a Argentina no periodo de 1998-99. São Paulo, 2005. Tese (Doutorado em Economia) - Programa de Pós-Graduação em Economia, Departamento de Economia, Faculdade de Economia, Administração e Contabilidade da Universidade de São Paulo.

HOLANDA, Marcos C.; CORRÊA, Márcio V. Contagion Effect in Latin America Big Three. São Paulo: Estudos Econômicos, v.33, n.3, p.509-529, julho-setembro, 2003.

MARKOWITZ, Harry. Portfolio Selection. Journal of Finance, v.7, n.1, p.77-91, mar., 1952.

MURTA, Luiz Roberto; BRASIL, Gutemberg Hespanha; SAMOHYL, Robert Wayne. Crise Monetária Brasileira de 1999: uma Análise Econométrica Realizada com Base em Elementos Teóricos de Modelos de Crises Monetárias de Primeira e Segunda Geração. Anais do XXXI Encontro Nacional de Economia, 2003.

NEAL, Larry; WEIDENMIER, Marc. Crises in the Global Economy from Tulips to Today: Contagion and Consequences. National Bureau of Economic Research (NBER) Working Paper, n. 9147, September, 2002.

PERICOLI, Marcello; SBRACIA, Massimo. A primer on financial contagion. Oxford: Journal of Economic Surveys, v.17, n.4, 2003.

REINHART, Carmen M.; ROGOFF, Kenneth S. Oito Séculos de Delirios Financeiros: desta vez é diferente. 2 ed. Rio de Janeiro: Elsevier, 2010.

SHARPE, William. Capital Asset Prices: A Theory of Market Equilibrium Under Conditions of Risk. Journal of Finance, v. 19, n. 3, 1964. 
ANEXO - Principais medidas para a aplicação dos testes de Forbes e Ribobon (2002) e Corsetti, Pericoli e Sbracia (2005)

A.1 - Matriz de cargas fatoriais

Component Matrix ${ }^{a}$

\begin{tabular}{|l|r|}
\hline & $\begin{array}{c}\text { Compone } \\
\text { nt }\end{array}$ \\
\cline { 2 - 2 } & \multicolumn{1}{|c|}{1} \\
\hline RAFRSUL &, 669 \\
RARG &, 518 \\
RAUS &, 849 \\
RBRA &, 605 \\
RCAN &, 696 \\
RCHI &, 615 \\
RCOL &, 358 \\
RESP &, 827 \\
REUA &, 645 \\
RFRA &, 857 \\
RHON &, 521 \\
RITA &, 807 \\
RJAP &, 445 \\
RRUS &, 508 \\
RTWN &, 322 \\
\hline
\end{tabular}

Extraction Method: Principal Component Analysis.

a. 1 components extracted.

A. 2 - Principais variáveis (Crise da Ásia)

\begin{tabular}{|cccc|}
\hline nt & 359 & Crise da Ásia & \\
$\mathrm{nc}$ & 100 & & \\
$\operatorname{Var}(\mathrm{rj} / \mathrm{t})$ & 1,6276 & $\operatorname{Var}(\mathrm{rj} / \mathrm{c})$ & 17,6739 \\
$\operatorname{Var}(\mathrm{zj} / \mathrm{t})$ & 1,4053 & $\operatorname{Var}(\varepsilon \mathrm{c} / \mathrm{c})$ & 14,1208 \\
$\operatorname{Var}(\mathrm{f} / \mathrm{t})$ & 0,2303 & $\operatorname{Var}(\mathrm{f} / \mathrm{c})$ & 1,4161 \\
& & & \\
$\delta$ & 9,8588 & & \\
$\lambda \mathrm{t}$ & 22,4942 & & \\
$\lambda \mathrm{c}$ & 36,7579 & & \\
\hline
\end{tabular}

\section{A.3 - Principais variáveis (Crise da Rússia)}

\begin{tabular}{|cccc|}
\hline & & Crise Rússia & \\
$\mathrm{nt}$ & 147 & & \\
$\mathrm{nc}$ & 38 & $\operatorname{Var}(\mathrm{rj} / \mathrm{c})$ & 34,9974 \\
$\operatorname{Var}(\mathrm{rj} / \mathrm{t})$ & 17,3087 & $\operatorname{Var}(\mathrm{\varepsilon j} / \mathrm{c})$ & 31,9622 \\
$\operatorname{Var}(\mathrm{\varepsilon j} / \mathrm{t})$ & 15,3254 & $\operatorname{Var}(\mathrm{f} / \mathrm{c})$ & 3,1268 \\
$\operatorname{Var}(\mathrm{f} / \mathrm{t})$ & 0,8011 & & \\
& & & \\
$\delta$ & 1,0220 & & \\
$\lambda \mathrm{t}$ & 74,0279 & & \\
$\lambda \mathrm{c}$ & 39,5567 & & \\
\hline
\end{tabular}


A.4 - Principais variáveis (Crise do Brasil 1999)

\begin{tabular}{|c|c|c|c|}
\hline \multicolumn{4}{|c|}{ Crise Brasil 1999} \\
\hline nt & 75 & & \\
\hline $\mathrm{nc}$ & 51 & & \\
\hline $\operatorname{Var}(\mathrm{rj} / \mathrm{t})$ & 16,0239 & $\operatorname{Var}(\mathrm{rj} / \mathrm{c})$ & 29,7376 \\
\hline $\operatorname{Var}(\varepsilon j / t)$ & 12,6216 & $\operatorname{Var}(\varepsilon j / c)$ & 25,0065 \\
\hline $\operatorname{Var}(\mathrm{f} / \mathrm{t})$ & 1,8610 & $\operatorname{Var}(\mathrm{f} / \mathrm{c})$ & 1,3174 \\
\hline$\delta$ & 0,8558 & & \\
\hline$\lambda \mathrm{t}$ & 18,5182 & & \\
\hline$\lambda c$ & 51,8271 & & \\
\hline
\end{tabular}

A.5 - Principais variáveis (Crise da Bolha da Internet)

\begin{tabular}{|cccc|}
\hline \multicolumn{4}{c|}{ Crise Bolha da Internet } \\
$\mathrm{nt}$ & 310 & & \\
$\mathrm{nc}$ & 291 & $\operatorname{Var}(\mathrm{rj} / \mathrm{c})$ & 2,0750 \\
$\operatorname{Var}(\mathrm{rj} / \mathrm{t})$ & 1,3879 & $\operatorname{Var}(\mathrm{zj} / \mathrm{c})$ & 1,2493 \\
$\operatorname{Var}(\mathrm{\varepsilon j} / \mathrm{t})$ & 0,9555 & $\operatorname{Var}(\mathrm{f} / \mathrm{c})$ & 0,9050 \\
$\operatorname{Var}(\mathrm{f} / \mathrm{t})$ & 0,6670 & & \\
& & & \\
$\delta$ & 0,4951 & & \\
$\lambda \mathrm{t}$ & 3,4468 & & \\
$\lambda \mathrm{c}$ & 3,3217 & & \\
\hline
\end{tabular}

A.6 - Principais variáveis (Crise de 11 de setembro de 2001)

\begin{tabular}{|cccc|}
\hline \multicolumn{3}{c|}{ Crise 11 de setembro } \\
$\mathrm{nt}$ & 99 & & \\
$\mathrm{nc}$ & 411 & $\operatorname{Var}(\mathrm{rj} / \mathrm{c})$ & 2,3293 \\
$\operatorname{Var}(\mathrm{rj} / \mathrm{t})$ & 1,0687 & $\operatorname{Var}(\mathrm{zj} / \mathrm{c})$ & 1,3962 \\
$\operatorname{Var}(\mathrm{gj} / \mathrm{t})$ & 0,7087 & $\operatorname{Var}(\mathrm{f} / \mathrm{c})$ & 1,2172 \\
$\operatorname{Var}(\mathrm{f} / \mathrm{t})$ & 0,4291 & & \\
& & & \\
$\delta$ & 1,1796 & & \\
$\lambda \mathrm{t}$ & 3,9744 & & \\
$\lambda \mathrm{c}$ & 2,7603 & & \\
\hline
\end{tabular}

\section{A.7 - Principais variáveis (Crise da Argentina)}

\begin{tabular}{|cccc|}
\hline $\mathrm{n}$ & Crise Argentina & \\
$\mathrm{nc}$ & 138 & & \\
$\operatorname{Var}(\mathrm{rj} / \mathrm{t})$ & 5,1650 & $\operatorname{Var}(\mathrm{rj} / \mathrm{c})$ & 13,9121 \\
$\operatorname{Var}(\mathrm{zj} / \mathrm{t})$ & 4,1548 & $\operatorname{Var}(\mathrm{zj} / \mathrm{c})$ & 13,2634 \\
$\operatorname{Var}(\mathrm{f} / \mathrm{t})$ & 0,7560 & $\operatorname{Var}(\mathrm{f} / \mathrm{c})$ & 0,8518 \\
& & & \\
$\delta$ & 1,6935 & & \\
$\lambda \mathrm{t}$ & 20,4816 & & \\
$\lambda \mathrm{c}$ & 58,0323 & & \\
\hline
\end{tabular}


A. 8 - Principais variáveis (Crise do Brasil 2002)

\begin{tabular}{|c|c|c|c|}
\hline \multicolumn{4}{|c|}{ Crise Brasil 2002} \\
\hline nt & 183 & & \\
\hline $\mathrm{nc}$ & 362 & & \\
\hline $\operatorname{Var}(\mathrm{rj} / \mathrm{t})$ & 3,6439 & $\operatorname{Var}(\mathrm{rj} / \mathrm{c})$ & 4,5618 \\
\hline $\operatorname{Var}(\varepsilon j / t)$ & 2,7391 & $\operatorname{Var}(\varepsilon j / c)$ & 3,7830 \\
\hline $\operatorname{Var}(\mathrm{f} / \mathrm{t})$ & 0,7666 & $\operatorname{Var}(\mathrm{f} / \mathrm{c})$ & 1,1702 \\
\hline$\delta$ & 0,2519 & & \\
\hline$\lambda \mathrm{t}$ & 9,7558 & & \\
\hline$\lambda c$ & 8,8267 & & \\
\hline
\end{tabular}

\section{A.9 - Principais variáveis (Crise do Subprime)}

\begin{tabular}{|c|c|c|c|}
\hline \multicolumn{4}{|c|}{ Crise Subprime } \\
\hline nt & 468 & & \\
\hline $\mathrm{nc}$ & 429 & & \\
\hline $\operatorname{Var}(\mathrm{rj} / \mathrm{t})$ & 0,4314 & $\operatorname{Var}(\mathrm{rj} / \mathrm{c})$ & 5,1290 \\
\hline $\operatorname{Var}(\varepsilon j / t)$ & 0,2481 & $\operatorname{Var}(\varepsilon j / c)$ & 2,9518 \\
\hline $\operatorname{Var}(\mathrm{f} / \mathrm{t})$ & 0,4902 & $\operatorname{Var}(\mathrm{f} / \mathrm{c})$ & 2,9614 \\
\hline$\delta$ & 10,8883 & & \\
\hline$\lambda \mathrm{t}$ & 1,2178 & & \\
\hline$\lambda c$ & 2,3986 & & \\
\hline
\end{tabular}

